\title{
Contracting with Feedback
}

Lin, Tse-chun, Qi Liu, and Bo Sun

Please cite paper as:

Lin, Tse-chun, Qi Liu, and Bo Sun (2015).

Contracting with Feedback

International Finance Discussion Papers 1143.

http://dx.doi.org/10.17016/IFDP.2015.1143

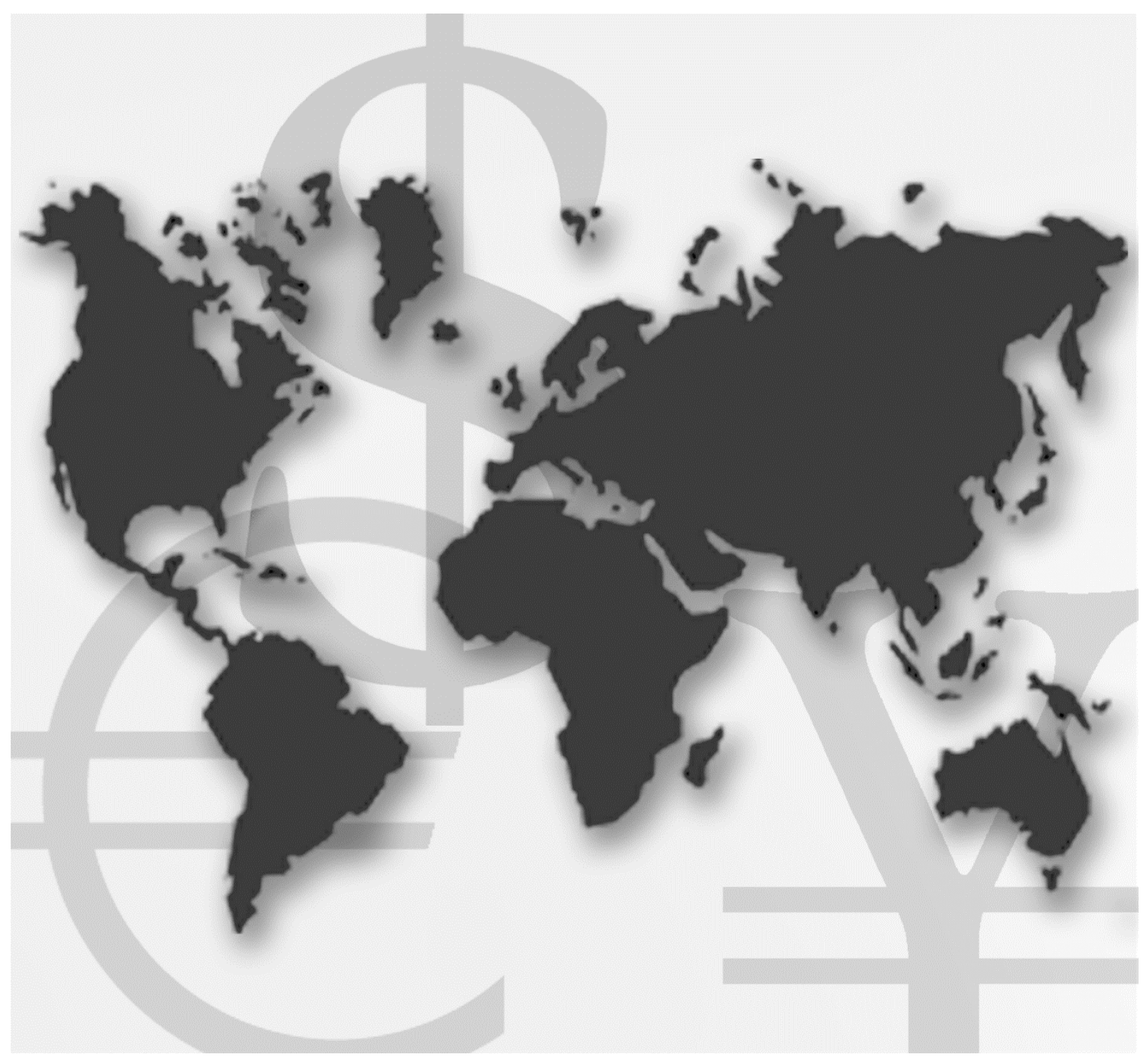

\section{International Finance Discussion Papers}

Board of Governors of the Federal Reserve System

Number 1143

August 2015 


\title{
Board of Governors of the Federal Reserve System \\ International Finance Discussion Papers
}

Number 1143

August 2015

\section{Contracting with Feedback}

\author{
Tse-chun Lin, Qi Liu, and Bo Sun
}

NOTE: International Finance Discussion Papers are preliminary materials circulated to stimulate discussion and critical comment. References to International Finance Discussion Papers (other than an acknowledgment that the writer has had access to unpublished material) should be cleared with the author or authors. Recent IFDPs are available on the Web at www.federalreserve.gov/pubs/ifdp/. This paper can be downloaded without charge from the Social Science Research Network electronic library at www.ssrn.com. 


\title{
Contracting with Feedback
}

\author{
Tse-chun Lin, Qi Liu, and Bo Sun
}

\begin{abstract}
:
We study the effect of financial market conditions on managerial compensation structure. First, we analyze the optimal pay-for-performance in a model in which corporate decisions and firm value are both endogenous to trading due to feedback from information contained in stock prices. In a less frictional financial market, the improved information content of stock prices helps guide managerial decisions, and this information substitutes out part of the direct incentive provision from compensation contracts. Thus, the optimal pay-for-performance is lowered in response to reductions in market frictions. Second, we test our theory using two quasi-natural experiments and find evidence that is consistent with the theory. Our results indicate that the financial market environment plays an important role in shaping CEO compensation structure.
\end{abstract}

Keywords: Feedback effect, CEO compensation, Transaction costs, Reg-SHO Pilot program, Decimalization

JEL classifications: G30, J33

One of the authors is a staff economist in the Division of International Finance, Board of Governors of the Federal Reserve System, Washington, D.C. 20551 U.S.A. The views in this paper are solely the responsibility of the authors and should not be interpreted as reflecting the views of the Board of Governors of the Federal Reserve System or of any other person associated with the Federal Reserve System. 


\title{
Contracting with Feedback
}

\author{
Tse-Chun $\operatorname{Lin}^{\mathrm{a} *}$ Qi Liu ${ }^{\mathrm{b} \dagger}$ Bo Sun ${ }^{\mathrm{C}} \neq$

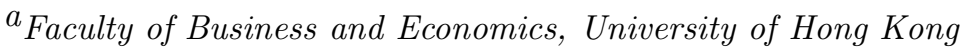 \\ ${ }^{b}$ Peking University \\ ${ }^{c}$ Federal Reserve Board
}

August 2015

\begin{abstract}
We study the effect of financial market conditions on managerial compensation structure. First, we analyze the optimal pay-for-performance in a model in which corporate decisions and firm value are both endogenous to trading due to feedback from information contained in stock prices. In a less frictional financial market, the improved information content of stock prices helps guide managerial decisions, and this information substitutes out part of direct incentive provision in compensation contracts. Thus, the optimal pay-for-performance is lowered in response to reductions in market frictions. Second, we test our theory using two quasi-natural experiments and find evidence that is consistent with the theory. Our results indicate that the financial market environment plays an important role in shaping CEO compensation structure.
\end{abstract}

JEL classification: G30, J33.

Keywords: Feedback effect, CEO compensation, Transaction costs, Reg-SHO Pilot program, Decimalization

We thank workshop participants at Baruch College, Cornell University, Carnegie Mellon University, Federal Reserve Board, SAIF, NBER Summer Institute, Junior Theory conference at Kellogg, and UVA-Richmond Fed Research Conference for helpful comments. Tse-Chun Lin gratefully acknowledges research support from the Faculty of Business and Economics at the University of Hong Kong and the Research Grant Council of the Hong Kong SAR government. We thank Xiaorong Ma for excellent research assistance. We also thank Russell Investments for providing the list of Russell 3000 index. The views expressed herein are the authors' and do not necessarily reflect the opinions of the Board of Governors of the Federal Reserve System.

*E-mail address: tsechunlin@hku.hk

${ }^{\dagger}$ E-mail address: qiliu@gsm.pku.edu.cn

${ }^{\ddagger}$ E-mail address: bo.sun@frb.gov 


\title{
Contracting with Feedback
}

\begin{abstract}
We study the effect of financial market conditions on managerial compensation structure. First, we analyze the optimal pay-for-performance in a model in which corporate decisions and firm value are both endogenous to trading due to feedback from information contained in stock prices. In a less frictional financial market, the improved information content of stock prices helps guide managerial decisions, and this information substitutes out part of direct incentive provision in compensation contracts. Thus, the optimal pay-for-performance is lowered in response to reductions in market frictions. Second, we test our theory using two quasi-natural experiments and find evidence that is consistent with the theory. Our results indicate that the financial market environment plays an important role in shaping CEO compensation structure.
\end{abstract}

Keywords: Feedback effect, CEO compensation, Transaction costs, Reg-SHO Pilot program, Decimalization

JEL Classifications: G30, J33. 


\section{Introduction}

In the standard contracting theory, incentive provisions in compensation contracts are the sole determinant of managerial decisions. With agency frictions, a strong pay-for-performance is thus typically required to induce desired managerial actions. A growing literature on the feedback effect demonstrates an additional mechanism that affects corporate decisions: managers can learn new information from market prices and use this information to guide their real decisions such as investment and acquisition. ${ }^{1}$ As the feedback effect directly influences managerial behavior, compensation should optimally adjust, taking into account the information content of stock prices. The objective of this paper is to study how the feedback effect would influence the design of managerial compensation.

In this paper, we first analyze the optimal pay-for-performance in a model in which both corporate decisions and firm value are endogenous to trading due to feedback from information revealed in stock prices. Specifically, we embed a market microstructure model into a contracting framework to derive the contracting implications of the feedback effect. We then test our theory using two quasi-natural experiments and find coherent evidence that trading frictions in financial markets play an important role in shaping executive compensation.

A key insight of our model is that information acquisition in the financial market substitutes out part of incentive provision in compensation contracts. By aggregating the information of many market participants, the financial market can guide managers in their real decisions, such as investments, by conveying information that is not otherwise available to managers. Anticipating that managers are guided by the market, there is less necessity for shareholders to provide direct incentives in compensation.

\footnotetext{
${ }^{1}$ See Bond, Edmans, and Goldstein (2012) for a review.
} 
In addition to the aforementioned substitution between pay and feedback, an endogenous response of financial market speculators to executive pay generates an amplification mechanism that further lowers pay-for-performance. That is, a weak-powered compensation leads to increased uncertainty in firm value, which raises speculators' expected return from learning and hence incentivizes information acquisition in the financial market. To take advantage of this incentivizing effect, shareholders optimally reduce incentive pay in executive compensation.

Our model produces three new testable implications. First, reductions in trading frictions in the financial market encourage informed trading and enable prices to better guide managers in their real decisions, rendering incentive compensation less necessary and thus lowering CEO pay-for-performance. Second, when agency frictions are more severe, the information produced in the financial market is more useful in correcting managerial bias, and the effect of changing market conditions on pay is therefore stronger. Last, reductions in trading frictions weaken the positive association between incentive pay and firms' investment opportunities. The reason is that when the information content of stock prices improves, the financial market can guide managers on which investments are profitable by revealing additional information, and a strong-powered pay is no longer necessary to induce optimal investment when opportunities expand.

Our model implications are new to the literature, and we test them empirically. The endogenous nature of information acquisition in the stock market poses empirical challenges to identifying the causal effects of feedback on the design of managerial incentives. To address this issue, we use two quasi-natural experiments that reduce market trading frictions to test our theory — Regulation SHO (Reg SHO) and decimalization. Reg SHO removed short-sale restrictions for a randomly selected subset of firms during the program, while decimalization 
reduced minimum tick size and generated a shift from the fractional pricing system to the decimal pricing system in U.S. stock exchanges. Both regulatory changes have been shown to be effective in reducing transaction costs in the financial market. ${ }^{2}$

We find confirming evidence that the experiments that change financial market conditions have a considerable effect on the design of managerial incentives. In particular, we find that managerial incentives in compensation, measured by scaled wealth-performance sensitivity (WPS), are significantly reduced in response to both Reg SHO and decimalization, after controlling for stock return volatility and institutional ownership ratio among various other firm characteristics. Moreover, the reductions in incentive pay in response to both regulatory changes are significantly greater for firms with stronger empire-building tendency, measured by the degree of financial flexibility firms face. Last, both regulatory changes lower the positive association between incentive pay and firms' investment opportunities, proxied by Tobin's Q. Taken together, this collective set of empirical results are most consistent with our theory and are difficult to be coherently explained by alternative theories on equity compensation. For example, the standard incentive-insurance tradeoff (Holmstrom and Milgrom (1987)) can suggest reductions in incentives in response to increased downside risk during Reg SHO program but has limited relevance for decimalization, and it is silent on the crosssectional variation in compensation responses depending on empire-building tendencies and investment opportunities.

Our paper hinges on the growing literature on the feedback effect from financial markets to real economic decisions. Previous studies have shown that the feedback effect influences

\footnotetext{
${ }^{2}$ Furfine (2003) finds that bid-ask spreads decline over $35 \%$ for actively traded stock. Bessembinder (2003) also finds that quoted bid-ask spreads decline substantially, particularly for heavily traded stocks. There has also been empirical evidence on strengthened stock liquidity and feedback effects after decimalization (for example, Fang, Noe, and Tice (2009)).
} 
many important corporate policies, including investment (Baker, Stein, and Wurgler (2003); Chen, Goldstein, and Jiang (2007); Bakke and Whited (2010)), acquisition (Luo (2005); Edmans, Goldstein, and Jiang (2012)), insider trading (Fishman and Hagerty (1992); Khanna, Slezak, and Bradley (1994)), decisions to seek public financing (Subrahmanyam and Titman (1999)), capital structure (Fulghieri and Lukin (2001); Chang and Yu (2010)), disclosure policy (Gao and Liang (2013)), and corporate governance (Gorton, Huang, and Kang (2013)). Given the role of the feedback effect in affecting corporate decisions, we argue that managerial pay contracts should — and can — adjust for the feedback effect, and we find supporting evidence that financial market conditions indeed influence the design of managerial incentives.

The literature broadly identifies two channels through which financial markets may affect real decisions. First, managers learn new information from stock prices and use this information to guide their real decisions, i.e., the feedback effect. Second, although managers do not learn new information from market prices, their incentives to take actions depend on the extent to which these actions will be reflected in stock prices. The existing papers that study managerial incentives, in conjunction with stock markets, analyze the second channel and focus on the information in stock prices regarding managerial effort and its role in structuring incentives, as in Diamond and Verrecchia (1982), Holmstrom and Tirole (1993), Kang and Liu (2010), and Jayaraman and Milbourn (2012) for example. ${ }^{3}$ The literature on managerial pay largely ignores the first channel that features the transmission of information, which is at the heart of our analysis. Thus, our analysis provides a complementary view on the role of financial market conditions in structuring CEO pay, and presents evidence suggest-

\footnotetext{
${ }^{3}$ This line of research suggests a complementary relationship between market informativeness and incentive pay, which is different from the substitution relationship derived in our model and documented in our empirical analysis.
} 
ing that the substitution between information provision by the stock market and incentive compensation can be a dominating consideration. ${ }^{4}$

In addition, recent studies illustrate that an external governance mechanism exists when blockholders, by increasing price efficiency through trading or exit, help exert governance and improve firm value (e.g., Admati and Pfleiderer (2009), Edmans (2009), and Edmans and Manso (2011)). But how does such an external governance mechanism translate into changes in managerial compensation? The answer remains ambiguous. It can be argued that equity incentives are more necessary in order to make blockholders' threat of exit relevant for managers, likely suggesting an opposite relationship to what we derive. In addition, Admati and Pfleiderer (2009) show that although the blockholder alleviates the agency problem of the manager taking a bad action (e.g., shirking), the blockholder can also make it more difficult to motivate the manager to take a good action (e.g., exerting effort). Empirically, recent studies show that such an external governance mechanism would actually work better in firms with higher incentive pay (Bharath, Jayaraman and Nagar (2013); Chang, Lin and Ma (2014); Edmans, Fang, and Zur (2013)). Our analysis is instead centered around the feedback effect, which emphasizes managerial learning from stock prices, and derives clear implications for managerial compensation.

The rest of the paper is organized as follows. Section 2 describes the model. In Section

\footnotetext{
${ }^{4}$ Our theory highlights that incentive contracting and information acquisition in the financial markets are strategic substitutes, as the marginal benefit of granting incentives in contracts decreases when information revealed in stock markets can guide managerial decisions. In addition, an amplification mechanism exists when ex-ante overinvestment propensity increases market speculators' incentives to gather information, which is reminiscent of the traders' incentives studied in Dow, Goldstein, and Guembel (2011). In their model, speculators have stronger incentives to produce information about firms' investment opportunities when these investments are more likely ex-ante. This generates an informational amplification effect of shocks to firm value, rendering a market breakdown possible in response to a small decline in a firm's fundamentals. Our paper complements theirs by showing that this claim also amplifies the response in compensation when the financial market environment changes.
} 
3, we take compensation as given, and we analyze managerial incentives to make investments and financial-market speculators' incentives to acquire information and trade. We also illustrate the formulation of stock prices in the presence of feedback. In Section 4, we examine the design of managerial incentives in compensation and derive testable predictions. Section 5 tests our model predictions in an experiment setup. Section 6 concludes. Proofs are provided in the appendix.

\section{The Model}

\subsection{Environment}

To study the role of feedback in affecting the design of managerial incentives, we embed a market microstructure model into a contracting framework. Consider a one-period economy with a firm whose stock is traded in the financial market. Shareholders design a compensation contract to maximize the expected firm value net of pay. The firm's manager has an empirebuilding motive and makes an investment decision to maximize his own utility. The economic state determines the final payoffs from investments. The one-step departure from a standard contracting environment is that our model includes three types of agents in a market for the firm's stock: a financial-market speculator, a liquidity trader, and a market maker. The speculator decides how much information to acquire and trades in the stock market to maximize his trading profits. A liquidity trader trades the firm's stock merely for liquidity reasons. The market maker sets the market price to break even in expectation. All agents are risk neutral, and the risk-free rate and reservation utility are normalized to zero.

The timeline of Figure 1 chronicles the sequence of events in the model. At the beginning 
Figure 1: Model Timeline

\begin{tabular}{llllll}
\hline Contract & Manager & Speculator & Market & Manager & Manager is \\
is offered; & learns $p$ and & \& liquidity & maker sets & makes & compensated \\
observed & speculator & traders & stock price & investment & based on \\
by all & produces & submit & based on & based on & firm value; \\
agents & information & their orders & $\begin{array}{l}\text { aggregate } \\
\text { orders }\end{array}$ & $\begin{array}{l}p \text { and stock } \\
\text { price }\end{array}$ & $\begin{array}{l}\text { speculator } \\
\text { collects profits }\end{array}$ \\
& & & &
\end{tabular}

of the period, shareholders offer a compensation contract to the manager, which is observed by all agents in the economy. The underlying economic state, denoted by $S$, can be either good or bad, $S \in\{g, b\}$, and the manager privately knows the probability that the state is good, denoted by $p$. The probability of a good state $(p)$ is a random variable, and all the other agents only know the distribution of $p$. After observing the contract, a speculator decides how much information to produce, and he trades in the stock market if he becomes informed about the state. A liquidity trader simultaneously submits his market order, which is unrelated to the state realization. The market maker observes the total order flow; the market maker cannot distinguish market orders from the speculator and those from the liquidity trader, and he will set the price such that, given the total order submitted, his profit at the end of the period is expected to be zero. After observing the stock price, the manager subsequently chooses one of two mutually exclusive investment opportunities, $I \in\left\{I_{H}, I_{L}\right\}$, where $I_{H}>I_{L}$. At the end of the period, the payoffs to all parties are realized based on the state realization.

The key ingredient in our contracting model is the feedback from stock prices to corporate investment. The speculator may have insights into the state realization that were missed by the manager. The manager observes the share price and subsequently uses this information to update his belief about the profitability of investment opportunities. Note that the feedback 
effect is taken into account by the representative shareholder when designing the contract, by the speculator when acquiring information, and by the market maker when setting the price. We now describe the firm's investment problem and the trading process in more detail.

Representative shareholder There is a representative risk-neutral shareholder that designs compensation to maximize the shareholder payoff, which is realized firm value net of managerial pay. When designing compensation, the shareholder understands how the manager makes decisions based on incentives in compensation and how the financial market responds to incentives in managerial pay. To derive transparent and testable implications, we maximize tractability by building a deliberately parsimonious model in which the investment choice is binary and the contract is restricted to include base salary and shares.

The shareholder has access to two mutually exclusive investment opportunities, $I \in$ $\left\{I_{H}, I_{L}\right\}, I_{H}>I_{L}$, where $I_{H}$ and $I_{L}$ represent high and low investment, respectively. Low investment can be thought of as no investment, and risky expansion can be implemented by making high investment. We interpret $\left(I_{H}-I_{L}\right)$ as the firm's investment opportunities. ${ }^{5}$

The shareholder faces uncertainty over the payoff realization under each possible investment. In particular, there are two possible states: $S \in\{g, b\}$ ("good" and "bad"). Investment of $I_{i} \operatorname{costs} I_{i}$, and the investment payoff at the end of the period is $I_{i}(1+\eta)$ if the state is good and $I_{i}(1-\eta)$ if the state is bad, where $0<\eta<1$, for $i \in\{H, L\}$. That is, with a baseline firm value of $V_{0}$, the firm has a terminal value of $V_{0}+\eta I_{i}$ in the good state and $V_{0}-\eta I_{i}$ in the bad state, for $i \in\{H, L\}$. We abstract away from bankruptcy risk by assuming that firm value is always positive.

The shareholder hires a manager to make the investment decision, because the manager

\footnotetext{
${ }^{5}$ Low investment can be also interpreted as divesting.
} 
privately knows the probability of a good state $(p)$. The probability $p$ is a random variable, and all the other agents only know that $p$ is uniformly distributed on the interval $[0,1]$. The contract consists of a base salary and $\beta$ shares of stock. As will be detailed later, we also assume non-negativity of compensation; therefore, the base salary is zero at the optimum. Thus, we focus on the pay-for-performance $\beta$ when characterizing the efficient contracting outcome. The compensation contract implements a target investment policy, denoted by $q$. We will show in Section 3.1 that there is a one-to-one correspondence between pay-forperformance $\beta$ and target investment policy $q$. As the compensation contract is observed by all agents in the model, the target investment policy $q$ is also known to all agents in the model.

Traders and market maker Trading occurs in the stock market after the contract is offered and observed by everyone. There is a financial market speculator who acquires information at a quadratic cost. In particular, the speculator can choose to observe the state with probability $\theta$ at a $\operatorname{cost} C(\theta)=\frac{1}{2} A \theta^{2}$. That is, with probability $\theta$, the speculator perfectly observes the state of nature; with probability $(1-\theta)$, the speculator's costly effort results in no learning. The speculator will optimally decide how much information to produce, i.e. the value of $\theta$, to maximize his trading profits.

The speculator submits market orders, $z_{s} \in\{-1,0,1\}$, to maximize his trading profits. If the speculator observes the state is good, he will submit a buy order of size 1. If the speculator observes a bad state, he will submit a sell order of size 1. The speculator does not trade if he does not learn the state. The liquidity trader simultaneously submits either a buy or sell order of size 1 with equal probabilities: $z_{\ell} \in\{-1,1\}{ }^{6}$

\footnotetext{
${ }^{6}$ Allowing the liquidity trader to have an option of no trading does not change our results. As in the standard market microstructure literature, we only require the liquidity trader to be probabilistically present.
} 
The market maker can only observe total order flow $X=z_{s}+z_{\ell}$ but not its individual components $z_{s}$ and $z_{\ell}$. Possible order flows are $X \in\{-2,-1,0,1,2\}$. In a perfectly competitive market making profession, the market maker sets the price equal to the expected firm value, based on available information, including information contained in the total order flow and the incentives in the compensation contract: $P(X, q)=E[V \mid X, q]$, where $V$ denotes the end-of-period firm value. In particular, the aggregate order flow may contain information on the state realization when a speculator is present.

As is standard in the feedback literature (e.g., Dow, Goldstein, and Guembel (2011), Goldstein, Ozdenoren, and Yuan (2011), and Edmans, Goldstein, and Jiang (2015)), trades are anonymous, and the speculator cannot credibly communicate his private information to the manager outside the trading process. It is clear that the speculator has neither incentive nor credibility to do so in our model since he has no initial stake in the firm; instead, he wishes to use his information to maximize the trading profits.

Manager The manager is hired to make investment decisions and is privately informed about the probability of a good state $(p)$. The risk-neutral manager makes an investment decision to maximize his own expected utility. The manager's utility is of the form $U_{m}(q, I)=$ $\beta V+\delta I$, where $V$ denotes the end-of-period firm value and $I \in\left\{I_{H}, I_{L}\right\}$ is the investment. The first term represents incentives in the compensation. The second term represents the manager's empire-building motive, that is, the manager derives private benefits from making investments, which are proportional to the size of invested capital. ${ }^{7}$ Private benefits are not

\footnotetext{
${ }^{7}$ It has been suggested by many papers that managers engage in value-destroying empire building, e.g., Baumol (1959), Marris (1964), Williamson (1964), Jensen (1986, 1993), Stulz (1990), Zwiebel (1996), Titman et al. (2004), Masulis et al. (2007), and Billett et al. (2011). This assumption of empire-building managers is popularly used in theoretical literature: Grossman and Hart (1988), Harris and Raviv (1990), Chang (1993), Bizjak et al. (1993), Hart and Moore (1995), Shleifer and Vishny (1997), Garvey (1997), Baldenius (2003), Aggarwal and Samwick (2006), Eisfeldt and Rampini (2008), Allen et al. (2012), and Baldenius et al. (2014).
} 
in terms of the consumption good and cannot be seized. The manager's reservation utility is normalized to zero, and the manager also has limited liability, that is, his compensation cannot be negative.

In addition to the manager's private information regarding the state distribution $(p)$, the manager may extract information about the state from the financial market. If the stock price reveals the speculator's information regarding state realization, the manager will rationally update his belief and choose the corresponding optimal investment. Otherwise, the manager follows the target investment policy $q$ implied by the compensation contract given his private information $p$.

\subsection{Equilibrium}

The Perfect Bayesian Nash Equilibrium we study is defined as follows: (i) an information production strategy and a trading strategy by the speculator, $T:\{\beta, q\} \rightarrow \theta ; z_{s} \rightarrow\{-1,0,1\}$, that maximize his expected trading profits given the compensation contract, the price-setting rule, the manager's investment strategy, and the speculator's information about the realization of the state; (ii) an investment strategy by the manager, $M:\{\beta, p, P\} \rightarrow I$, that maximizes his expected utility given the compensation contract, his private knowledge about the future state, and the information revealed in the order flow; (iii) a price-setting strategy by the market maker, $R:\{X, q\} \rightarrow P$, that allows him to break even in expectation given the information in the total market orders, the manager's investment strategy, and the compensation contract; and (iv) a compensation contract that includes a payment structure and a target investment strategy by the representative shareholder, $\xi:\{M, T, R\} \rightarrow\{\beta, q\}$, that maximizes expected firm value net of compensation given the manager's strategy, the 
speculator's strategy, and the price-setting rule. Moreover, (v) the manager and the market maker use Bayes' rule to update their beliefs from the order they observe in the financial market. Finally, (vi) all agents have rational expectations, and each player's belief about the other players' strategies is correct in equilibrium.

\section{Investment policy and feedback effect}

In this section, we first take compensation as given and derive the investment policy implied by the compensation contract. That is, we analyze how the manager responds to the incentives in compensation, absent of feedback. Second, for a given compensation contract, we study the speculator's decision to acquire information and trade in the market. After solving the manager's investment problem and the speculator's choice of information acquisition, we will endogenize the design of compensation contracts in the next section, taking into account the effects of compensation on both managerial investment and information acquisition in the stock market.

\subsection{Investment policy implied by compensation}

To solve the model, we start by analyzing the investment policy implied by a given compensation contract, absent of the feedback effect. Because the investment payoffs are symmetric about zero, that is, the net profits in the good state are identical in size to the net loss in the bad state, the first best investment policy is to take high investment if $p \geq 1 / 2{ }^{8}$ With the managerial empire-building motive, it is straightforward to show that investment policy

\footnotetext{
${ }^{8}$ The expected value of future state is $\eta p-\eta(1-p)=\eta(2 p-1) \geq 0$ when $p \geq 1 / 2$.
} 
implemented by contract also has a threshold property — the manager takes high investment $\left(I_{H}\right)$ if and only if $p$ is at least as large as a threshold, denoted by $q .{ }^{9}$ For a given investment policy with a threshold $q$, the expected firm value, denoted by $\mathcal{V}(q)$, is derived as follows:

$$
\begin{aligned}
\mathcal{V}(q) & =V_{0}+\int_{0}^{q} I_{L}[\eta p+(-\eta)(1-p)] d p+\int_{q}^{1} I_{H}[\eta p+(-\eta)(1-p)] d p \\
& =V_{0}+\left(I_{H}-I_{L}\right) \eta\left(q-q^{2}\right) .
\end{aligned}
$$

It is clear that the first best investment policy is $q=1 / 2$. With empire-building motive, the manager has a tendency to choose high investment $\left(I_{H}\right)$ for private benefits. For $q \leq 1 / 2$, although increasing $q$ (closer to the first best) enhances the firm value, it also increases compensation necessary to induce $q$. This consideration leads to a $q$ that is lower than the first best level in the presence of agency frictions. We focus on $q<1 / 2$ throughout the paper, as $q \geq 1 / 2$ is off the equilibrium path. ${ }^{10}$

Specifically, to implement a target investment policy with a threshold $q$ - high investment is taken if and only if $p \geq q$ - incentive compatibility requires that the manager prefers high investment for all $p \geq q$, which implies that the manager is indifferent between high and low investment when $p=q$ :

$$
\beta\left[q I_{H} \eta-(1-q) I_{H} \eta\right]+\beta V_{0}+\delta I_{H}=\beta\left[q I_{L} \eta-(1-q) I_{L} \eta\right]+\beta V_{0}+\delta I_{L}
$$

Recall that compensation is fully characterized by the degree of pay-for-performance $(\beta)$ in

\footnotetext{
${ }^{9}$ The investment policy has a threshold property in our model, because the manager's utility differential between making high and low investment is strictly increasing in $p$.

${ }^{10}$ We focus on $q<1 / 2$ for two reasons. First, as we will show later, the incentive-compatible incentives are represented by $\beta=\delta /[(1-2 q) \eta]$ for any $q$, and $q \geq 1 / 2$ is not implementable. Second, even if $q \geq 1 / 2$ is implementable, shareholders have no incentives to do so, because increasing $q$ above $1 / 2$ reduces both expected payoffs from investment and the amount of informed trading. Therefore, we only need to consider the case where $q<1 / 2$.
} 
our model, due to the assumption of linearity and non-negativity. The incentive-compatible pay-for-performance is thus given by $\beta=\frac{\delta}{(1-2 q) \eta}$.

Lemma 1. (Pay-for-performance) For any given recommended investment policy $q(\leq 1 / 2)$, the incentive-compatible pay-for-performance is represented by $\beta=\frac{\delta}{(1-2 q) \eta}$.

(i) $\beta$ is increasing in the target investment policy $(q): \frac{\partial \beta}{\partial q}>0$.

(ii) $\beta$ is increasing in managerial empire-building tendency $(\delta): \frac{\partial \beta}{\partial \delta}>0$.

As the target investment policy is to take high investment only if $p \geq q$, a high $q$ implies a low likelihood that the manager takes high investment. To implement a higher $q$ that is closer to the first best strategy, a stronger-powered compensation is therefore required to mitigate empire-building motives. By the same token, when the manager derives greater private gains from high investment (i.e., a larger $\delta$ ), it is necessary to offer more monetary incentives in compensation to curb overinvestment by the manager.

\subsection{Information acquisition and trading}

In this subsection, we analyze the speculator's information acquisition and price formulation in the financial market. The speculator acquires information $(\theta)$ at a quadratic $\operatorname{cost} C(\theta)=$ $\frac{1}{2} A \theta^{2}$. The more cost the speculator incurs, the more likely he learns the state perfectly. With probability $\theta$, the speculator perfectly observes the state. He will buy if the state is good and sell if the state is bad. ${ }^{11}$ With probability $(1-\theta)$, the speculator fails to learn

\footnotetext{
${ }^{11}$ Bond, Edmans, and Goldstein (2012) and Edmand, Goldstein, and Jiang (2015) argue that speculators may under-acquire, under-use, or misuse their information. This argument admittedly weaken our results quantitatively but would not overturn our mechanism. In addition, we show in Appendix B that a trading strategy identical to that in our current setting can arise in a more general version of our model.
} 
anything and consequently does not trade. ${ }^{12}$ We interpret $A$ as a policy parameter that represents a broad notion of transaction costs. A larger $A$ in our model captures a more frictional financial market.

\begin{tabular}{|l|l|l|l|l|l|}
\hline $\begin{array}{l}\text { State learned } \\
\text { by speculator }\end{array}$ & $\begin{array}{l}\text { Total market } \\
\text { order }\end{array}$ & $\begin{array}{l}\text { Probability } \\
\text { of event }\end{array}$ & Stock price & $\begin{array}{l}\text { Manager's } \\
\text { investment }\end{array}$ & $\begin{array}{l}\text { Speculator's } \\
\text { profits }\end{array}$ \\
\hline Good & 2 buys & $p \theta / 2$ & $I_{H} \eta+V_{0}$ & $I_{H}$ & 0 \\
\hline Good & 1 buy 1 sell & $p \theta / 2$ & $\mathcal{V}(q)$ & $I_{H}$ iff $p \geq q$ & $\begin{array}{l}I_{H} \eta+V_{0}-\mathcal{V}(q) \text { if } p \geq q, \\
I_{L} \eta+V_{0}-\mathcal{V}(q) \text { if } p<q\end{array}$ \\
\hline Bad & 2 sells & $(1-p) \theta / 2$ & $-I_{L} \eta+V_{0}$ & $I_{L}$ & 0 \\
\hline Bad & 1 buy 1 sell & $(1-p) \theta / 2$ & $\mathcal{V}(q)$ & $I_{H}$ iff $p \geq q$ & $\begin{array}{l}\mathcal{V}(q)+I_{H} \eta-V_{0} \text { if } p \geq q, \\
\mathcal{V}(q)+I_{L} \eta-V_{0} \text { if } p<q\end{array}$ \\
\hline None & 1 buy or 1 sell & $1-\theta$ & $\mathcal{V}(q)$ & $I_{H}$ iff $p \geq q$ & 0 \\
\hline
\end{tabular}

Table 1: Trading and feedback

Following kyle (1985), orders are submitted simultaneously to a market maker who sets the price and absorbs the order flows out of his inventory. A critical departure from Kyle (1985) is that firm value is endogenous in our model, because it depends on the manager's action, which is in turn based on information revealed in the stock prices. There are five possible order flows on the equilibrium path as shown in Table 1: 1) two buy orders; 2) two sell orders; 3) one buy order and one sell order; 4) one buy order; and 5) one sell order. We can see that information contained in total order flows is identical to that in prices; thus, observing total order flows is equivalent to observing stock prices. Since we are interested in the feedback effect, we focus on the equilibrium where the manager responds optimally to

\footnotetext{
${ }^{12}$ The speculator probabilistically observes the state perfectly is a simplifying assumption made for tractability. This information structure simplifies the manager's learning. In an alternative model that features a noisy signal of speculators as in Kyle (1985), the manager will assign weights on his own signal and the speculator's signal (revealed in the stock price), depending on the relative precision of the signals. The mechanisms in the current paper will carry through. Our current information structure is standard in the feedback literature, such as in Goldstein, Ozdenoren, and Yuan (2011), which maximizes tractability without sacrificing the essence of learning dynamics.
} 
the information in the order flow. ${ }^{13}$

If there are two buy orders in the market, everyone in the economy understands that the speculator has observed a good state. The manager will update his belief and optimally take high investment. The market maker understands the feedback effect and sets the share price equal to $V_{0}+\eta I_{H}$. If there are two sell orders in the market, the manager understands that the speculator has observed a bad state, and therefore optimally takes low investment. The market maker rationally sets the share price equal to $V_{0}-\eta I_{L}$. In all the other cases, the total order flow does not reveal the speculator's information, because it gets contaminated with the liquidity trader's order. The manager follows the investment policy implied by the contract $(q)$ given his private information $p$. The stock price is equal to the firm value without the feedback effect, i.e., $\mathcal{V}(q)$, in those cases.

We characterize the expected firm value and the speculator's profits in each possible case on the equilibrium path in Table 1. From Table 1, we can see that the speculator can extract information rents, denoted by $\Pi$, only when his private information is not fully priced in. The speculator's expected trading profits can be calculated as follows:

$$
\begin{aligned}
E[\Pi(q) \mid \theta]= & \int_{0}^{q}\left[\frac{p \theta}{2}\left(\eta I_{L}+V_{0}-\mathcal{V}(q)\right)+\frac{(1-p) \theta}{2}\left(\mathcal{V}(q)+\eta I_{L}-V_{0}\right)\right] d p \\
& +\int_{q}^{1}\left[\frac{p \theta}{2}\left(\eta I_{H}+V_{0}-\mathcal{V}(q)\right)+\frac{(1-p) \theta}{2}\left(\mathcal{V}(q)+\eta I_{H}-V_{0}\right)\right] d p \\
= & \frac{\theta \eta}{2}\left(I_{H}-q\left(I_{H}-I_{L}\right)\right) .
\end{aligned}
$$

\footnotetext{
${ }^{13}$ We focus on the equilibrium in which the speculator trades in line with his information. Bond, Edmans, and Goldstein (2012) and Edmand, Goldstein, and Jiang (2015) argue that speculators may under-acquire and under-use their information. We abstract away from this possibility in this initial attempt to study the contracting implications of feedback, and our results are robust to incorporating a richer trading strategy on the part of the speculator.
} 
It is straightforward to see that the speculator's information rents decrease with $q$. A smaller $q$ implies an ex-ante larger likelihood of high investment. The state-contingent rise and fall are also correspondingly large for high investment, raising variability in firm value. Increased uncertainty in firm value increases the value of information and creates opportunities for trading profits.

The speculator's problem is to maximize his trading profits net of the cost, given the contract:

$$
\max _{\theta} E[\Pi(q) \mid \theta]-\frac{1}{2} A \theta^{2}=\frac{\theta \eta}{2}\left(I_{H}-q\left(I_{H}-I_{L}\right)\right)-\frac{1}{2} A \theta^{2} .
$$

The solution to the speculator's problem represents the optimal information production, which is characterized in the following lemma. This lemma also represents the speculator's reaction function, given managerial contract.

Lemma 2. (Information production) Given the contract, the optimal amount of information production by the speculator is represented by

$$
\theta=\frac{\eta}{2 A}\left(I_{H}-q\left(I_{H}-I_{L}\right)\right)
$$

(i) Information produced $(\theta)$ decreases in the target investment policy $(q): \frac{\partial \theta}{\partial q}<0$;

(ii) Information produced $(\theta)$ decreases in the transaction cost $(A): \frac{\partial \theta}{\partial A}<0$.

Recall that trading profits decrease with $q$, thus the amount of information the speculator produces also decreases with $q$. A lower $q$ implies that high investment is more likely to be undertaken. For large investments, the state-contingent rise and fall are also correspondingly large. Information about the state realization thus becomes more valuable in this case, 
increasing the marginal return from the speculator's learning. The speculator will therefore optimally produce more information in response to a weak-powered pay (corresponding to a lower $q)$.

When the transaction cost becomes lower (i.e., a smaller $A$ ), all else equal, the speculator's trading profits increase. In anticipation of higher trading profits, the speculator will optimally produce more information in response to lowered transaction costs.

\section{Optimal degree of pay-for-performance}

Now we turn to the design of managerial incentives, taking into account how incentive provision in compensation affects both managerial investment and information acquisition in the stock market. We focus on the degree of pay-for-performance $(\beta)$ in characterizing the optimal contract. As we will show later in this section, the intuitions of our mechanisms are transparent and general enough that we expect them to be present even in a more general environment. ${ }^{14}$

\subsection{Contracting without feedback}

As a benchmark, we first analyze the optimal compensation contract in the absence of feedback. The representative shareholder maximizes the expected terminal wealth. More

\footnotetext{
${ }^{14}$ To highlight the effect of information transmission from stock prices to managerial decisions, we abstract away from other general considerations related to price-based incentives, for example, more informative prices make better performance signals and thus serve as more effective incentive vehicles. These considerations have been analyzed in the literature and require prices to be formed after managerial actions, while we focus on pre-action prices that can guide managerial decisions by revealing information that is not otherwise available to managers. We discuss the contracting implications of alternative mechanisms in Section 5.2.3.
} 
specifically, the shareholder chooses the number of shares $(\hat{\beta})$, together with a target investment policy $(\hat{q})$, that maximize the firm value net of managerial pay. Formally, the optimal contract solves

$$
\max _{\beta, q} E[\text { Firm Value - managerial pay }]=(1-\beta)\left[V_{0}+\left(I_{H}-I_{L}\right) \eta\left(q-q^{2}\right)\right]
$$

subject to

$$
\hat{q}=\underset{q}{\arg \max } E\left[U_{m}(q, I)\right]
$$

and

$$
E\left[U_{m}(\hat{q}, I)\right] \geq 0
$$

The objective function is the shareholder's expected net payoff, which is expected firm value net of compensation. The first constraint $\left(I C_{I}\right)$ is the incentive compatibility constraint on investment strategy. The second constraint $(P C)$ is the participation constraint, which will be automatically satisfied given the zero reservation utility and non-negativity of compensation.

We have characterized the incentive-compatible pay-for-performance in Lemma 1 . The shareholder's problem is thus reduced to maximizing $(1-\beta) V(q)$ subject to $\beta=\frac{\delta}{(1-2 q) \eta}$. We characterize the equilibrium contract without feedback in Proposition 1.

Proposition 1. (Contracting without feedback) In the optimal contract without feedback, the optimal target investment policy $\hat{q}<1 / 2$ satisfies the following equation:

$$
1-2 \hat{q}-\frac{\delta}{\eta}-\frac{2 \delta\left(\hat{q}-\hat{q}^{2}\right)}{\eta(1-2 \hat{q})^{2}}-\frac{2 \delta V_{0}}{\eta^{2}\left(I_{H}-I_{L}\right)(1-2 \hat{q})^{2}}=0 .
$$

The optimal investment policy $\hat{q}$ and the corresponding managerial incentives $\hat{\beta}$ are both 
increasing in the firm's investment opportunities $\left(I_{H}-I_{L}\right)$.

Recall that in the first best case, as we discussed in Section 3.1, the optimal policy is $q=1 / 2$. With managerial empire-building incentives, a higher $q$ (toward $1 / 2$ ) increases the expected compensation, causing the optimal investment policy $(\hat{q})$ to be less than $1 / 2$ in equilibrium.

As in standard contracting theory, optimal managerial incentives in our model increase in response to enlarged investment opportunities. When investment opportunities expand, the investment payoff differential increases, and it is therefore more important to induce desired investment by offering additional incentives. Specifically, when the size differential $\left(I_{H}-I_{L}\right)$ increases, the optimal target investment policy $(\hat{q})$ will increase toward the first best level $(q=1 / 2)$. The pay-for-performance $(\hat{\beta})$ correspondingly increases.

\subsection{Contracting with feedback}

Now we turn to analyze the contracting problem, taking into account the feedback effect. We first analyze the components and properties of firm value. We then characterize the optimal pay-for-performance with feedback, and compare that to the no-feedback case. Last, we derive predications that will be empirically tested in Section 5 .

\subsubsection{Firm value}

Firm value is now endogenous to trading, as the manager optimally uses information revealed in stock prices to guide his investment decision. In particular, we can see from Table 1

that with probability $\frac{p \theta}{2}$, the manager learns from the market that the state is good and 
consequently takes high investment; with probability $\frac{(1-p) \theta}{2}$, the manager learns about the bad state and thus takes low investment. The expected firm value, denoted by $\mathcal{V}_{F}(q, \theta)$, can be derived as follows:

$$
\begin{aligned}
\mathcal{V}_{F}(q, \theta) & =E\left[\frac{p \theta}{2}\left(V_{0}+I_{H} \eta\right)+\frac{(1-p) \theta}{2}\left(V_{0}-I_{L} \eta\right)+\left(1-\frac{\theta}{2}\right) \mathcal{V}(q)\right] \\
& =\mathcal{V}(q)+\frac{\theta\left(I_{H}-I_{L}\right) \eta}{2}\left(\frac{1}{2}-q+q^{2}\right) .
\end{aligned}
$$

The first term in the firm value corresponds to the firm value absent of feedback $(\mathcal{V}(q))$. The second term represents the firm value derived from the feedback effect. That is, an increment in firm value can come from two sources in this environment: (i) the value created by directly implementing a desired investment policy using compensation and (ii) the value created by feedback from information revealed in stock prices. Shareholders search for an optimal mix of these two vehicles that deliver value. We derive properties of firm value in Lemma 3.

Lemma 3. (Firm value) Compared with the no-feedback case, the firm value with the feedback effect is higher, that is, $\mathcal{V}_{F}(q, \theta)>\mathcal{V}(q)$.

(i) Firm value increases in information produced in the stock market: $\frac{\partial \mathcal{V}_{F}}{\partial \theta}>0$;

(ii) The value of information created in the market increases in investment opportunities: $\frac{\partial \mathcal{V}_{F}}{\partial\left(I_{H}-I_{L}\right)}>0$

(iii) Incentives in compensation and information produced in the stock market are strategic substitutes: $\frac{\partial}{\partial \theta}\left(\frac{\partial \mathcal{V}_{F}}{\partial q}\right)<0$.

The information produced in the stock market constitutes firm value, because it guides 
managerial decisions and helps correct empire-building bias. As is standard in the market microstructure literature, the speculator in our model extracts information rents from the liquidity trader on average. Shareholders can free-ride on the information the speculator produces and benefit from it. The value of information produced in the market is proportional to the firm's investment opportunities, that is, $\left(I_{H}-I_{L}\right)$.

Proposition 3 also indicates that marginal benefits of using compensation are decreasing in the amount of information produced in the market. When there is more information produced in the market, the improved information content of stock prices helps guide the manager's investment decision. The set of circumstances in which compensation matters consequently shrinks. There is less necessity to use pay to induce desired actions. That is, managerial incentives in pay arrangements and information produced in the stock market are strategic substitutes.

\subsubsection{Optimal pay-for-performance}

The shareholder designs the compensation contract, keeping in mind how the manager reacts given the incentives as well as how the stock market responds to managerial pay. The

shareholder chooses the number of shares $(\hat{\beta})$, together with a target investment policy $(\hat{q})$, that maximize the firm value net of managerial pay. Formally, the optimal contract solves

$$
\max _{\beta, q}(1-\beta) \mathcal{V}_{F},
$$

subject to

$$
\beta^{*}=\frac{\delta}{\left(1-2 q^{*}\right) \eta},
$$


and

$$
E\left[U_{m}\left(q^{*}, I\right)\right] \geq 0
$$

The objective function is the shareholder's expected net payoff, which is expected firm value net of compensation. The first constraint $\left(I C_{I}^{*}\right)$ is the incentive compatiability constraint on investment strategy, taken from the results in Lemma 1. The second constraint $\left(P C^{*}\right)$ is the participation constraint, which will be automatically satisfied given the zero reservation utility and non-negativity of compensation.

To illustrate our main mechanism, we first take information production in the stock market $(\theta)$ as exogenous and study its influence on the design of managerial incentives. As information contained in stock prices and incentive pay are strategic substitutes in delivering efficient investment (Lemma 3), there is less need to provide direct incentives to ensure optimal decisions when the speculator exogenously produces more information, which clarifies the consequences of managerial actions and guides managers in their real decisions. Improving the information content of stock prices thus lowers managerial pay-for-performance, which is formalized in the following lemma. ${ }^{15}$

Lemma 4. (Substitution between information production and pay) Taking information production as exogenous, the target investment policy and optimal incentives in compensation both decrease in information produced in the stock market: $\frac{\partial q^{*}}{\partial \theta}<0, \frac{\partial \beta^{*}}{\partial \theta}<0$.

\footnotetext{
${ }^{15} \mathrm{~A}$ recent literature argues that an external governance mechanism exists when blockholders, by increasing price efficiency through trading or exit, help exert governance and improve firm value (e.g., Admati and Pfleiderer (2009), Edmans (2009), and Edmans and Manso (2011)). When the external governance mechanism is strengthened as stock prices become more informative about managerial actions, the target investment policy $\left(q^{*}\right)$ becomes higher because it is easier to implement desired investment. The impact on compensation $(\beta)$ is ambiguous: external governance provided by the threat of voting-with-feet helps align incentives, however, the incentivizing effect is stronger precisely when compensation is more tightly linked to stock prices, which may imply a complementary relationship between pay and market informativeness, opposite to what we find using the experiments that change the financial market environment.
} 
In our model, the information content of stock prices is endogenous in that the speculator optimally decides how much information to acquire $(\theta)$. We summarize the contracting results in Proposition 2.

Proposition 2. (Contracting with feedback) In the optimal contract in the presence of the feedback effect, the target investment policy satisfies $q^{*}<\hat{q}$, and the corresponding incentives in the contract are lower than those in the no-feedback case: $\beta^{*}<\hat{\beta}$.

Figure 2 illustrates this result. The dashed horizontal line represents the first best investment policy, that is, $q=1 / 2$. The curves represent shareholders' indifference curves $\left(\bar{u}=(1-\beta(q)) \mathcal{V}_{F}(q, \theta)\right)$, and indifference curves to the northeast offer higher utility. In the no-feedback case, there is no information produced in the market: $\theta=0$. The optimal contract is determined by the point at which shareholders' indifference curve becomes tangent on the vertical axis, that is, $\hat{q}(<1 / 2)$. In the presence of feedback, the speculator's information acquisition responds to managerial pay, which is denoted by the downward-sloping line derived in Lemma 2. The optimal contract with feedback is thus determined by the point at which shareholders' indifference curve becomes tangent on the speculator's reaction function, that is, $q^{*}$, which is lower than $\hat{q}$. As $\beta$ is strictly increasing in $q$, optimal pay-for-performance is lower with the feedback effect $\left(\beta^{*}\right)$ than that without it $(\hat{\beta})$.

To clearly show that feedback from stock prices lowers managerial incentives in compensation $(\beta)$, Figure 3 provides a graphic proof that separately illustrates the two mechanisms that deliver the result (mathematical proofs are in Appendix A). In Figure 3, we include the shareholders' reaction function, which is the dotted downward-sloping line with an intercept $\hat{q}$ on the vertical axis. This line represents how the shareholder structures compensation, taking information acquisition in the stock market as given. Shareholders' reaction function is downward-sloping, because marginal benefits of compensation are decreasing in the 


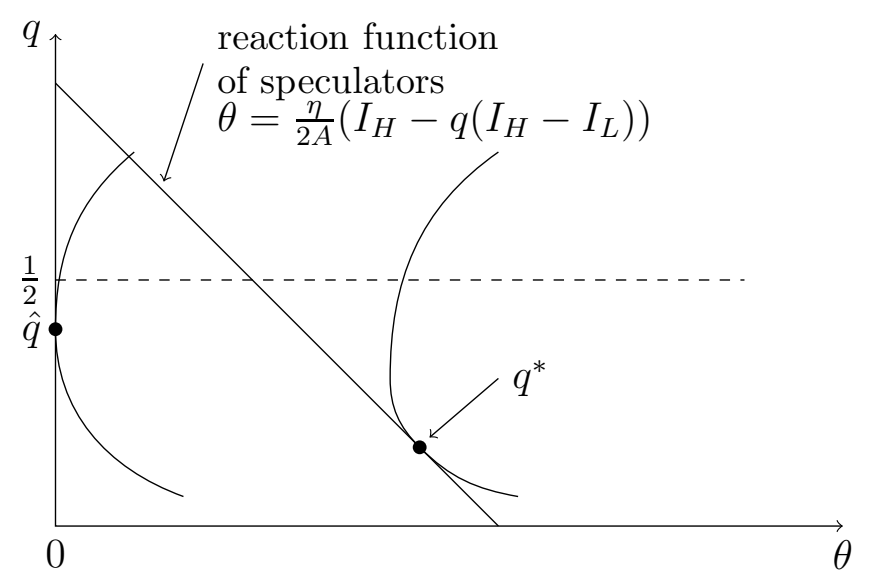

Figure 2: $q^{*}<\hat{q}$

amount of information produced in the market, as shown in Lemma 3. The point $E$ is where the two reaction functions cross each other and would represent the Nash equilibrium if the shareholder and the speculator moved simultaneously. The point $E$ corresponds to a level of $q$ (and hence $\beta$ ) that is already lower than the no-feedback case $(\hat{q})$. In addition, since a strong-powered compensation deters information acquisition (that is, $\frac{\partial \theta}{\partial q}<0$ ), the shareholder can take advantage of being the first mover and exploit the speculator by pushing the equilibrium down to $q^{*}$, offering even fewer incentives and inducing even more information from the stock market.

\subsection{Testable implications}

We now analyze the properties of compensation contracts in the presence of feedback, which will be empirically tested in the next section. We use the transaction cost in the stock market as a pivotal point to examine the contracting implications of the feedback effect. All else being equal, lowered trading frictions increase market speculators' trading profits 


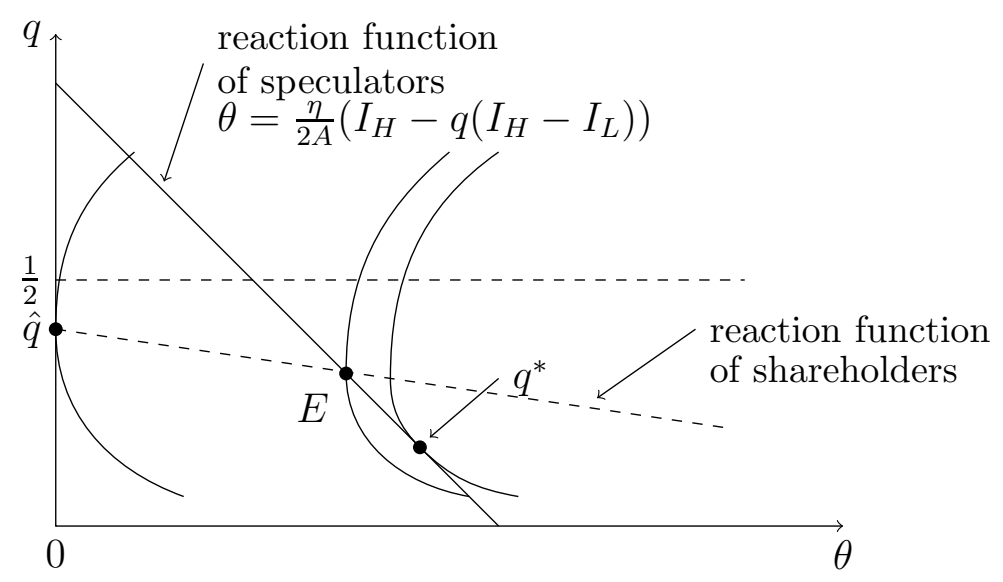

Figure 3: Graphic illustration for $q^{*}<\hat{q}$

and incentivize informed trading, which, in turn, affect both managerial compensation and information content of stock prices in equilibrium.

When the transaction cost decreases, all else being equal, there is more information produced in the stock market, which helps guide the manager in his investment decision, rendering incentives in compensation less necessary. The substitution between incentive pay and information acquisition in the market leads to less managerial incentives used in a less frictional market. In addition to the substitution effect, an amplification mechanism exists when information acquisition responds to pay. That is, as the speculator's action becomes more responsive to compensation strategy when the market becomes less frictional, a small reduction in incentive pay induces more information produced in the market, which consideration leads to an even lower pay-for-performance in equilibrium. We formally state this result below.

Implication 1. (Effect of market conditions on pay) The equilibrium pay-for-performance $\left(\beta^{*}\right)$ and the target investment policy implied by contract $\left(q^{*}\right)$ are both increasing in the 


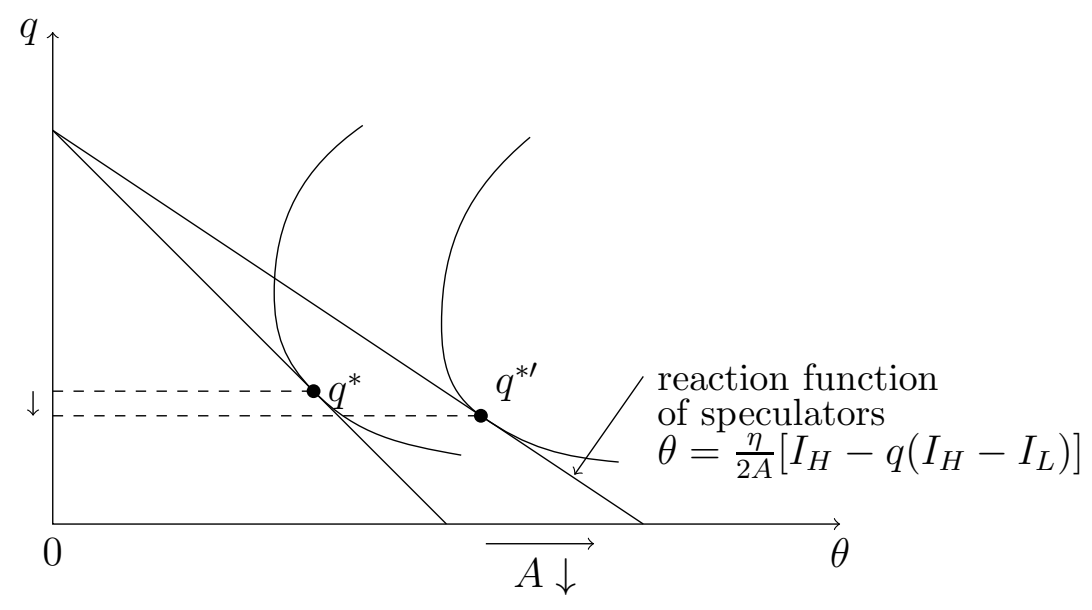

Figure 4: $\theta^{*} \uparrow, q^{*} \downarrow$ when $A \downarrow$

transaction $\operatorname{cost}(A): \frac{\partial \beta^{*}}{\partial A}>0 ; \frac{\partial q^{*}}{\partial A}>0$.

Figure 4 shows the effect of financial market conditions on managerial pay. When $A$ decreases, the speculator's reaction function $(\theta(q))$ becomes flatter - for any given compensation $(q)$, there is more information produced in the market. Shareholders' indifference curves are unaffected and now become tangent on the speculator's reaction function at a lower point $\left(q^{* \prime}\right)$. In equilibrium, there is less incentive pay and greater information acquisition in the market in response to reductions in the transaction cost.

In Figure 5, we illustrate the two mechanisms behind Implication 1: the substitution effect and the amplification effect. The substitution between incentive pay and feedback is reflected by the shift from the original equilibrium (represented by $q^{*}$ in Figure 5) to the point $D$, where a parallel shift of the speculator's reaction function becomes tangent on shareholders' indifference curve. A lowered transaction cost encourages information acquisition and trading, substituting out part of managerial incentives in compensation. An additional amplification mechanism is captured by the move from the point $D$ to the new 


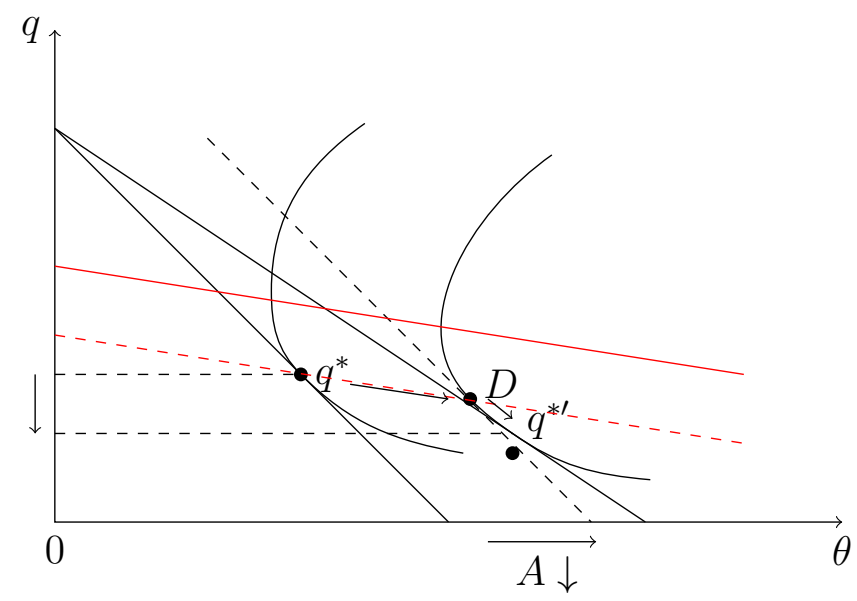

Figure 5: Graphic illustration of Implication 1

equilibrium, represented by $q^{* \prime}$, which is a result of the change in the slope of the speculator's reaction function. That is, when the market becomes less frictional (that is, a lower $A$ ), the speculator's information acquisition is more sensitive to managerial pay. Shareholders are able to take advantage of being the first mover and can induce additional information from the market by offering even lower incentives in compensation.

The information produced in the stock market is useful because it achieves investment efficiency ex-post by mitigating agency frictions and correcting for managerial bias. When managerial empire-building tendency is stronger (i.e., a larger $\delta$ ), information produced in the market is more valuable in mitigating managerial bias, and the effect of changes in the stock market environment on pay is therefore stronger. We formulate this result below and provide the sufficient condition in the proof in Appendix A. We also experiment numerically and cannot find a counterexample in a wide range of parameters.

Implication 2. (The role of managerial bias) Suppose that managerial empire-building tendency is not too large. The effect of transaction costs in the stock market on managerial 
compensation is stronger in firms with greater managerial empire-building tendency.

In addition, our model also produces implications for how the optimal pay-for-performance is influenced by the firm's investment opportunities. Without feedback, when the firm's investment opportunities expand, the payoff differential from the investment rises, and the increased importance of inducing optimal investment renders additional monetary incentives necessary (described in Proposition 1). With feedback, the market generates and reveals useful information that is relevant for corporate investment, guiding the manager through which investment to take. In particular, when the size differential $\left(I_{H}-I_{L}\right)$ is large, the speculator is particularly incentivized to produce information, because his potential gain is correspondingly large. There is less need to provide direct incentives when investment opportunities expand. In addition, as information acquisition is more responsive to managerial pay when the investment opportunity $\left(I_{H}-I_{L}\right)$ and thus potential trading profits increase, shareholders' desire to attract informed trading leads to an even more subdued response in pay to changes in the firm's investment opportunities.

Therefore, we expect that when the transaction cost drops, the response of CEO pay-forperformance to investment opportunity declines. Proposition 3 in Appendix A shows that this is the case when the drop in the transaction cost is sufficiently large. In particular, it proves that this response of pay to investment opportunities is positive when the transaction cost is above certain threshold (call it $\bar{A}$ ) and is negative when below another threshold (call it $\underline{A}$ ). Therefore, when $A$ drops from above $\bar{A}$ to below $\underline{A}$, the response declines. Although we have not been able to prove the decline in this response for small changes in the transaction cost, we have conducted extensive numerical investigations, and we have not found any counterexample even for small changes. Appendix A also provides a representative numerical example. We summarize this implication as the following. 
Implication 3. (Response of pay to investment opportunities) Reductions in transaction costs in the stock market lower the response in managerial compensation to the firm's investment opportunities.

The three model implications are new to the literature, and we will empirically examine them in the next section. It is certainly impossible to measure speculators' cost of producing information or their overall transaction costs. As a compromise, to proxy for reductions in the transaction cost, we use regulatory changes in trading rules that provide additional opportunities for market traders to trade and profit from their private information. We can also explicitly model a trading cost by assuming that trading additionally incurs a fixed cost if the speculator chooses to trade. We show in Appendix B that a separate trading cost shares similar properties as the parameter $A$ in the current model.

\subsection{Key drivers of model implications}

This subsection discusses which of the model's features are necessary for its key contracting results. In substance, there are three essential features in the model. First, managers learn new information from the stock prices and use that to guide their real decisions, that is, the feedback effect exists. ${ }^{16}$ Second, there are agency frictions present in managerial decisions. Third, market speculators' information acquisition responds to managerial pay. Our mechanisms, sufficiently produced by the first two elements and amplified by the third, are robust to various modifications of model assumptions.

\footnotetext{
${ }^{16}$ It is worth noting that the feedback effect only assumes that managers do not have complete knowledge and market speculators can reveal some information through trading that managers do not otherwise know, especially external information such as market demand for a firm's products and potential synergy with a target. We do not require the market to be better informed on an absolute basis.
} 
The first two building blocks — the feedback effect and agency frictions related to real decisions - are sufficient in delivering a substitution relationship between incentive contracting and information production in the stock market: When the market can aggregate and reveal more information, it makes the linkage between managerial actions and resulting outcomes more certain to managers ex-ante, which guides their real decisions and helps correct managerial bias, rendering incentive pay less necessary. This mechanism is not specific to any particular agency friction.

To model agency frictions, the current model features empire-building motives on the part of managers, which can be generalized to include various other agency conflicts related to real decisions. For example, an alternative version of the model could incorporate quietlife managers - as suggested in Hicks (1935) and Bertrand and Mullainathan (2003) among others - who may prefer to avoid the difficult decisions and costly efforts associated with shutting down old plants. An extension of the current model may allow for managers to exert effort to improve their own signals and actively learn about the state. The main intuition of our mechanisms - information provision by the market guides managers in their real decisions and thus substitutes out direct incentive provision in contracting — is robust to these alternative agency frictions.

The last element, which features an endogenous response of speculators' information acquisition to pay, further amplifies the effects of stock market conditions on pay. Anticipating a more uncertain firm payoff under a weak-powered pay regime, market speculators rationally produce more information in response to the increased return from their learning. Therefore, shareholders have less incentives to use high-powered compensation, which deters information production in the market. Our model implications do not hinge on this endogenous response of speculators and are robust to leaving information production exogenous 
(See Lemma 4).

\section{$5 \quad$ Empirical tests}

\subsection{Methodology and data}

In this section, we test our model implications using two quasi-natural experiments that better enable market participants to trade and profit from their private information in the U.S. stock market - Reg SHO program and decimalization. We use both regulatory changes to proxy for reductions in the transaction cost. The first experiment is that the U.S. Securities and Exchange Commission (SEC) launched Reg SHO program, which randomly selected onethird of the Russell 3000 Index firms as pilot firms and removed the short-sale restrictions ("uptick rule") for these pilot firms from May 2005 to August 2007.17 In selecting pilot firms, the SEC sorted the 2004 Russell 3000 first by listing market and then by average daily dollar volume from June 2003 through May 2004, and it selected every third company starting with the second within each listing market. ${ }^{18}$ The second experiment occurred when U.S. stock markets reduced the minimum tick size from 1/16 dollar to one cent in 2001. Empirical research shows that both experiments are effective in reducing bid-ask spreads (for example, Bessembinder (2003), Furfine (2003), Diether, Lee, and Werner (2009), and Alexander and

\footnotetext{
${ }^{17}$ The uptick rule is a trading restriction that states that short selling a stock is only allowed on an uptick. For the rule to be satisfied, the short must be either at a price above the last traded price of the security, or at the last traded price when the most recent movement between traded prices was upward (i.e. the security has traded below the last-traded price more recently than above that price).

${ }^{18}$ We begin by verifying that pilot firms represent a random draw from the Russell 3000 population. In the fiscal year before the pilot program, the pilot and non-pilot firms are similar in size, growth, corporate spending, profitability, leverage, and dividend payout, a finding also reported by Fang, Huang, and Karpoff (2014).
} 
Peterson (2008)). ${ }^{19}$

Following Edmans, Gabaix, and Landier (2009), we use the scaled wealth-performance sensitivity (WPS) to measure pay-performance sensitivities. WPS is the dollar change in CEO wealth for a one percentage point change in firm value, divided by annual compensation, and it is obtained from Alex Edmans' website. WPS is the elasticity of CEO pay to firm value and reflects changes in the value of a CEO's existing portfolio, including both new and existing grants. The key advantage of WPS is that it is independent of firm size and is comparable across firms and over time. Stock prices and returns data are from the Center for Research in Security Prices (CRSP). Accounting data are from COMPUSTAT. The institutional ownership ratio and institutional ownership concentration are from Thomson Reuters Institutional (13F) Holdings.

\subsection{Empirical results}

Our model has the following three main implications: a reduced transaction cost i) results in lower optimal pay-for-performance, (ii) has a stronger effect on pay-for-performance in firms with higher managerial empire-building tendencies, and iii) reduces the positive association between firms' investment opportunities and optimal pay-for-performance. We examine each of these implications in the following subsections.

\footnotetext{
${ }^{19}$ Among studies on Reg SHO program, Alexander and Peterson (2008) find that the effective spreads of trades initiated by short sellers decrease significantly for pilot stocks relative to control stocks. Diether, Lee, and Werner (2009) find that the relative bid depth increases significantly for NYSE pilot stocks. On decimalization, Furfine (2003) and Bessembinder (2003) find that bid-ask spreads decline substantially, particularly for heavily traded stocks. Fang, Noe, and Tice (2009) find that firm performance increases after decimalization, and they argue that this evidence is consistent with the notion that high stock liquidity reinforces the feedback effect by incorporating information into stock prices, which improves firm performance. In a related strand of literature, Bharath, Jayaraman, and Nagar (2013) find that decimalization enhances the positive association between blockholders' ownership and firm value, and they interpret this evidence as indicating that decimalization strengthens the governance role of block ownership via exit threats.
} 


\subsubsection{Optimal pay-for-performance}

We examine whether Reg SHO and decimalization lead to reductions in managerial incentives in compensation. First, we focus on the randomized experiment, that is, Reg SHO, and employ a difference-in-difference technique in the following regression:

$$
\beta_{i, t}=a_{i}+a_{t}+a_{1} \cdot I^{\text {PILOT }} \times I^{\text {During }}+a_{2} \cdot X_{i, t-1}+\epsilon_{i, t},
$$

where $a_{i}$ is a dummy for the firm fixed effect and $a_{t}$ is a dummy for the year fixed effect. $\beta$ is the scaled wealth-performance sensitivity (WPS), which is the dollar change in CEO wealth for a one percentage point change in firm value, divided by annual compensation (Edmans, Gabaix, and Landier (2009)). ${ }^{20} I^{\text {PILOT }}$ is a dummy, which equals 1 if firms are selected as Reg SHO pilot firms and 0 for the other firms in the Russell 3000 Index. ${ }^{21} I^{\text {During }}$ is a year dummy that equals 1 for 2005 through 2007 and 0 for 2001 through 2003. We exclude the year 2004, as that is the year when the SEC announced the pilot program. ${ }^{22} X_{i, t-1}$ denotes a set of control variables, including firm size, leverage ratio, dividend payout dummy, firm age, institutional ownership ratio, ratio of cash to asset, ratio of capital expenditure to asset, institutional ownership concentration ratio, and stock return volatility. We do not include $I^{\text {PILOT }}$ and $I^{\text {During }}$ separately in the regression, owing to a collinearity with yearand firm-fixed effects.

Columns (1) and (2) of Table 1 present the results from Equation (1). We find that the coefficient of $I^{\text {PILOT }} \times I^{\text {During }}$ is negative at a significance level of $1 \%$, suggesting that those firms selected as pilot firms experienced a reduction in managerial incentives in compensation

\footnotetext{
${ }^{20}$ WPS data is derived from ExecuComp data, which covers S\&P1500 firms.

${ }^{21}$ We employ the list of Russell 3000 Index members in June 2004.

${ }^{22}$ Including the year 2004 does not change our results.
} 
during the program compared with control firms. The economic magnitude of the effect is also sizable. The point estimate from the second column in Table 1 suggests that in response to a 100 percentage point change in firm value, the response of pay in pilot firms is 19.5 percentage points less than control firms during the experiment.

Second, we consider decimalization as an alternative exogenous shock to the transaction cost and carry out the following regression:

$$
\beta_{i, t}=a_{i}+a_{1} \cdot I^{\text {Decimal }}+a_{2} \cdot X_{i, t-1}+\epsilon_{i, t}
$$

where $a_{i}, \beta$, and $X_{i, t-1}$ are identically defined as those in Equation (1). $I^{\text {Decimal }}$ is a dummy variable that equals 1 for 2001 through 2007 and 0 for 1992 through 2000. We include all firms that have WPS data available.

Columns (3) and (4) of Table 1 present the results from Equation (2). We find that the coefficient of $I^{\text {Decimal }}$ is negative and significant. The economic magnitude is considerable: In response to a 100 percentage point change in firm value, the response of managerial incentives in compensation is 30 percentage points less in the post-decimalization period compared with the pre-decimalization period.

Our results highlight a contrast with Kang and Liu (2008) and Kang and Liu (2010), which document a positive association between managerial pay-for-performance and stock price informativeness and argue that more informative stock prices enhance the link between managerial pay and firm performance. ${ }^{23}$ Using regulatory changes to circumvent potential endogeneity issues, we show that the degree of pay-for-performance can actually be substi-

\footnotetext{
${ }^{23}$ Similarly, Jayaraman and Milbourn (2012) show that the CEOs pay-for-performance sensitivity with respect to stock prices is increasing in the liquidity of the stock.
} 
tuted out by information provision in the financial market. ${ }^{24}$

One might be concerned that stock volatility of pilot firms increased during the Reg SHO program, which leads to lowered incentives provided in compensation due to the standard risk-incentives tradeoff (Holmstrom and Milgrom (1987)). Having this in mind, we include stock return volatility as a control variable in our regressions, which does not affect our results. We will further discuss this alternative theory on equity compensation and its applications in our empirical analysis in Section 5.2.3.

\subsubsection{The role of managerial empire-building tendencies}

In this subsection, we examine whether managerial empire-building tendencies affect how incentive pay responds to changes in the transaction cost due to Reg SHO and decimalization. As the studies of the feedback effect have been concentrated on how stock prices help correct managerial investment decisions (Baker, Stein, and Wurgler (2003); Luo (2005); Chen, Goldstein, and Jiang (2007); Bakke and Whited (2010); and Bond, Edmans, and Goldstein (2012)), our model features managerial empire-building incentives and predicts that the effect of trading rule changes on pay structure is particularly pronounced in firms whose managers are more likely to overinvest.

We employ four proxies to measure managerial tendencies for empire-building (abbreviated as MTEB hereafter): negative New KZ Index (Hadlock and Pierce (2010)), negative KZ Index (Kaplan and Zingales (1997)), negative HP Index (Hadlock and Pierce (2010)), and negative firms' leverage ratio. The first three measures capture the degree of financial

\footnotetext{
${ }^{24}$ There may be unobserved firm characteristics that drive their results. For example, firms in which managerial effort affects firm performances more directly should grant stronger incentives in CEO pay. Meanwhile, the limited randomness in firm value may attract investors to trade the stock more frequently, improving price informativeness and stock liquidity.
} 
slackness firms face. Lower-level financial constraints provide more resources for managers to engage in empire-building. Similarly, managers at firms with lower leverage ratios have greater flexibility in undertaking large-scale investments and are thus more likely to do so, all else being equal.

First, we employ the Reg SHO program and conduct the regression as follows:

$$
\begin{aligned}
\beta_{i, t} & =a_{i}+a_{t}+a_{1} \cdot M T E B_{i, t-1} \times I^{\text {PILOT }} \times I^{\text {During }}+a_{2} \cdot I^{\text {PILOT }} \times I^{\text {During }} \\
& +a_{3} \cdot M T E B_{i, t-1} \times I^{\text {PILOT }}+a_{4} \cdot M T E B_{i, t-1} \times I^{\text {During }}+a_{5} \cdot M T E B_{i, t-1} \\
& +a_{6} \cdot X_{i, t-1}+\epsilon_{i, t},
\end{aligned}
$$

where $a_{i}, a_{t}, \beta, I^{\text {PILOT }}, I^{\text {During }}$, and $X_{i, t-1}$ are identically defined as those in Equation (1). $M T E B$ is a vector that proxies for managerial tendencies for empire-building, including negative New KZ Index, negative KZ Index, negative HP Index, and negative firms' leverage ratio. The larger the value of MTEB, all else being equal, the more resources available to managers to take large-scale projects and hence stronger managerial tendencies for empirebuilding.

As we focus on the impact of $M T E B s$ on the association between WPS and Reg SHO program, our main variable of interest is the coefficients of the interaction $M T E B_{i, t-1} \times$ $I^{\text {PILOT }} \times I^{\text {During }}$. In columns $(1),(2)$, and (4) of Table 2, we find that the coefficients of the three-way interaction are all negative and significant, implying that the reduction in managerial incentives in response to relaxation of short-sale constraints is strengthened when managers are ex-ante more likely to make large-scale investments. When we use the negative HP index to proxy for MTEB (column (3)), the coefficient of the three-way interaction is also negative as predicted, although not significant. 
Second, we employ decimalization as an alternative exogenous shock to the transaction cost in the stock market and conduct the regression as follows:

$$
\beta_{i, t}=a_{i}+a_{t}+a_{1} \cdot M T E B_{i, t-1} \times I^{\text {Decimal }}+a_{2} \cdot M T E B_{i, t-1}+a_{4} \cdot X_{i, t-1}+\epsilon_{i, t},
$$

where $a_{i}, a_{t}, \beta, I^{\text {Decimal }}, X_{i, t-1}$, and $M T E B$ are identically defined as those in Equation (2). Table 3 presents the results. The coefficients of $M T E B_{i, t-1} \times I^{\text {Decimal }}$ are all negative and significant. That is, the post-decimalization reduction in WPS is stronger in firms whose managers are ex-ante more likely to make large investments.

\subsubsection{Tobin's Q and pay-for-performance}

Now we investigate whether exogenous shocks to transaction costs would reduce the positive association between WPS and firms' investment opportunities, proxied by Tobin's Q. First, we examine the effect of Reg SHO program using the following regression:

$$
\begin{aligned}
\beta_{i, t} & =a_{i}+a_{t}+a_{1} \cdot Q_{i, t-1} \times I^{\text {PILOT }} \times I^{\text {During }} \\
& +a_{2} \cdot Q_{i, t-1} \times I^{\text {PILOT }}+a_{3} \cdot Q_{i, t-1} \times I^{\text {During }} \\
& +a_{4} \cdot I^{\text {PILOT }} \times I^{\text {During }}+a_{5} \cdot Q_{i, t-1}+a_{6} \cdot X_{i, t-1}+\epsilon_{i, t},
\end{aligned}
$$

where $a_{i}, a_{t}, \beta, I^{P I L O T}, I^{\text {During }}$, and $X_{i, t-1}$ are identically defined as those in Equations (1). $Q$ denotes Tobin's $\mathrm{Q}$, calculated as the ratio of the market value of assets to the book value of assets, where the market value of assets is defined as the book value of assets (data 6 in Compustat) plus the market value of common equity (data 25 times data 199 in Compustat) less the book value of common equity (data 60 in Compustat) and balance sheet deferred 
taxes (data 74 in Compustat).

Our main variable of interest is the coefficient of the three-way interaction term $Q \times$ $I^{\text {PILOT }} \times I^{\text {During }}$, which captures whether the reduction in the transaction cost affects the positive relation between Tobin's Q and WPS. Column (2) of Table 4 shows that the coefficient, $a_{1}$, is negative and significant at $10 \%$ significance level, suggesting that Reg-SHO program reduces the positive association between Tobin's Q and WPS in pilot firms.

Second, we examine the effect of decimalization on the association between investment opportunities and managerial incentives, and we conduct the regression as follows:

$$
\begin{aligned}
\beta_{i, t} & =a_{i}+a_{t}+a_{1} \cdot Q_{i, t-1} \times I^{\text {Decimal }}+a_{2} \cdot Q_{i, t-1} \\
& +a_{3} \cdot X_{i, t-1}+\epsilon_{i, t},
\end{aligned}
$$

where $a_{i}, a_{t}, \beta, I^{\text {Decimal }}$, and $X_{i, t-1}$ are defined as identical to those in Equation (2). $Q$ denotes Tobin's Q, calculated as the ratio of the market value of assets to the book value of assets, where the market value of assets is defined as the book value of assets (data 6 in Compustat) plus the market value of common equity (data 25 times data 199 in Compustat) less the book value of common equity (data 60 in Compustat) and balance sheet deferred taxes (data 74 in Compustat).

Column (4) of Table 4 shows that the coefficient of the interaction $Q \times I^{\text {Decimal }}$ is negative and significant at the $10 \%$ level. This result echoes the Reg SHO analysis that a lowered transaction cost reduces the effect of firms' investment opportunities on managerial pay.

Taken together, our empirical analysis using both experiments (i.e., Reg SHO and decimalization) provides confirming evidence that changes in the stock market environment 
affect the design of managerial compensation, and this set of results collectively point to the feedback effect as a natural, coherent explanation. A review of alternative theories on the role of financial markets for compensation design reveals the difficulty in consistently producing all the three data patterns. For example, the risk-sharing consideration can lower incentives when faced with increased downside risk for pilot firms during Reg SHO, but it has limited relevance in the case of decimalization and is silent regarding how firms differ in compensation responses based on empire-building resources and investment opportunities. The monitoring role of stock markets highlighted in Holmstrom and Tirole (1993) suggests that equity compensation is more effective in offering incentives when stock prices incorporate more information about managerial actions, predicting a complementary relationship between incentive pay and market informativeness. Similarly, the governance mechanism based on "voting with feet" would in theory render the use of equity compensation more necessary to make blockholders' threat of exit relevant for managers, and it empirically requires the presence of blockholders to take effect. In sum, the three patterns we find in the data - incentives reduce in a less frictional financial market and reduce more in firms with greater empire-building and investment opportunities — are most consistent with our theory with the feedback effect.

\section{Conclusion}

Existing studies have analyzed managerial compensation and the feedback effect in isolation. As the feedback effect directly influences managerial behavior, compensation should and can optimally adjust for it. We study the contracting implications of the feedback effect, and we show, both theoretically and empirically, that when the financial market becomes 
less frictional, information acquisition in the stock market substitutes out part of incentive provision in compensation.

When the information content of stock prices improves, the financial market can offer managers better guidance on key moves such as investments and acquisitions by providing additional information. As the feedback effect helps mitigate managerial bias in decision making, there is therefore less necessity to provide direct incentives in compensation. In addition, the endogenous response of information acquisition in the stock market generates an amplification mechanism that enhances the effect of changing financial market environments on managerial pay. That is, a weak-powered pay increases uncertainty in investment payoffs and incentivizes information acquisition in the market, which leads to even lower incentives in compensation arrangements.

Our empirical investigation using regulatory shocks to the transaction cost in the stock market shows that changes in the financial market play an important role in determining managerial compensation. Our study provides confirming evidence that information provision by the stock market contributes to compensation responses during these market experiments, and yet it does not aim to attribute the changes entirely to the feedback effect. Given the mounting empirical evidence for the importance of the feedback effect, our goal is to initiate a first attempt to examine how and whether financial market conditions affect the design of executive compensation due to this information transmission mechanism. Certainly more work lies ahead to better understand the quantitative importance of the feedback effect in shaping executive pay. 


\section{Appendix}

\section{A Proofs}

Proof of Proposition 1: For brevity, we denote $\Delta=I_{H}-I_{L}$ in the following proofs. Without informed trading, the shareholders' objective is to maximize

$$
\left(1-\frac{\delta}{(1-2 q) \eta}\right) \mathcal{V}(q)=\left(1-\frac{\delta}{(1-2 q) \eta}\right)\left[\Delta \eta\left(q-q^{2}\right)+V_{0}\right]
$$

Taking the first-order derivative w.r.t $q$ yields

$$
1-2 q-\frac{\delta}{\eta}-\frac{2 \delta\left(q-q^{2}\right)}{\eta(1-2 q)^{2}}-\frac{2 \delta V_{0}}{\eta^{2} \Delta(1-2 q)^{2}}=0
$$

Denote the left-hand side of the above equation by $f(q, \Delta)$. Since $f(q, \Delta)=0$, we obtain that $\frac{\partial f}{\partial \Delta}+\frac{\partial f}{\partial q} \frac{\partial q}{\partial \Delta}=0$. Since at the maximum we must have $\frac{\partial f}{\partial q}<0$, the sign of $\frac{\partial q}{\partial \Delta}$ is the same as the sign of $\frac{\partial f}{\partial \Delta}$. Note that $\frac{\partial f}{\partial \Delta}=\frac{2 \delta V_{0}}{\eta^{2} \Delta^{2}(1-2 q)^{2}}>0$, so the optimal policy $\hat{q}$ is increasing in $\Delta$, and thus $\hat{\beta}=\frac{\delta}{(1-2 \hat{q}) \eta}$ is also increasing in $\Delta . \square$

\section{Proof of Lemma 3:}

(i) $\operatorname{As} \frac{\theta\left(I_{H}-I_{L}\right) \eta}{2}\left(\frac{1}{2}-q-q^{2}\right)>0$, for $0<q<1 / 2$, we have $\mathcal{V}_{F}(q, \theta)>\mathcal{V}(q), \forall q$.

(ii) $\frac{\partial \mathcal{V}_{F}}{\partial \theta}=\frac{\Delta \eta}{2}\left(\frac{1}{2}-q+q^{2}\right)>0$. Given $\theta, \frac{\partial\left(\mathcal{V}_{F}-\mathcal{V}(q)\right)}{\partial\left(I_{H}-I_{L}\right)}=\frac{\theta \eta}{2}\left(\frac{1}{2}-q+q^{2}\right)>0$.

(iii) $\frac{\partial}{\partial \theta}\left(\frac{\partial \mathcal{V}_{F}}{\partial q}\right)=\frac{\Delta \eta}{2}(-1+2 q)<0$.

\section{Proof of Proposition 2:}

For simplicity, we define $\delta^{\prime}=\delta / \eta$, then $\beta=\frac{\delta}{(1-2 q) \eta}=\frac{\delta^{\prime}}{1-2 q}$. Also, $0<\beta<1$ 
implies that $0<\delta^{\prime}<1$. The shareholders' objective is to maximize $(1-\beta) \mathcal{V}_{F}$, where $0<\beta=\frac{\delta^{\prime}}{1-2 q}<1$. Note that

$$
\frac{\partial}{\partial q}\left[\left(1-\frac{\delta^{\prime}}{1-2 q}\right) \mathcal{V}(q)\right]=\Delta \eta\left[1-2 q-\delta^{\prime}-\frac{2 \delta^{\prime}\left(q-q^{2}\right)}{(1-2 q)^{2}}-\frac{2 \delta^{\prime} V_{0}}{\eta \Delta(1-2 q)^{2}}\right]
$$

is decreasing in $q$ for $q<\frac{1}{2}$. So for any $\frac{1}{2}>q \geq \hat{q}, \frac{\partial}{\partial q}\left[\left(1-\frac{\delta^{\prime}}{1-2 q}\right) \mathcal{V}(q)\right] \leq 0$. Hence, for any $\frac{1}{2}>q \geq \hat{q}$,

$$
\frac{\partial}{\partial q}\left[\left(1-\frac{\delta^{\prime}}{1-2 q}\right) \mathcal{V}_{F}\right] \leq \frac{\partial}{\partial q}\left[\left(1-\frac{\delta^{\prime}}{1-2 q}\right) \frac{\theta \Delta \eta}{2}\left(\frac{1}{2}-q+q^{2}\right)\right]<0 .
$$

So $q^{*}<\hat{q}$. Thus, $\beta^{*}=\frac{\delta^{\prime}}{\left(1-2 q^{*}\right) \eta}<\hat{\beta}$.

Proof of Implication 1: Plugging $\theta=\frac{\eta}{2 A}\left(I_{H}(1-q)+I_{L} q-\frac{2 c}{\eta}\right)$ into $\mathcal{V}_{F}(q, \theta)$ yields that maximizing $\left(1-\frac{\delta^{\prime}}{1-2 q}\right) \mathcal{V}_{F}(q, \theta)$ is equivalent to maximizing

$F(q, x)=\left(1-\frac{\delta^{\prime}}{1-2 q}\right)\left[-\Delta q^{3}+\left(2 I_{H}-I_{L}-B\right) q^{2}-\left(\frac{3}{2} I_{H}-\frac{1}{2} I_{L}-B\right) q+\frac{I_{H}}{2}+\frac{V_{0} B}{\Delta \eta}\right]$.

Denote $f(q, x)=\frac{\partial F}{\partial q}$, where $x$ refers to the parameter $I_{H}, I_{L}$, or $A$. Then we have $\frac{\partial f}{\partial x}+$ $\frac{\partial f}{\partial q} \frac{\partial q}{\partial x}=0$. Since at the maximum $q^{*}$, we must have $\frac{\partial f}{\partial q}<0$, the sign of $\frac{\partial q}{\partial x}$ is the same as the sign of $\frac{\partial f}{\partial x}$. We first can compute that

$$
\frac{\partial f}{\partial I_{H}}=\frac{1}{(1-2 q)^{2}}\left[(1-2 q)^{2}\left(-3 q^{2}+4 q-\frac{3}{2}\right)-b^{\prime}\left(4 q^{3}-7 q^{2}+4 q-\frac{1}{2}\right)+\frac{2 \delta^{\prime} V_{0} B}{\Delta^{2} \eta}\right] .
$$


So we obtain that

$$
\frac{\partial}{\partial q}\left[(1-2 q)^{2} \frac{\partial f}{\partial I_{H}}\right]=(1-2 q)\left[-4\left(-3 q^{2}+4 q-\frac{3}{2}\right)+\left(1-2 q-\delta^{\prime}\right)(4-6 q)\right]>0 .
$$

So $(1-2 q)^{2} \frac{\partial f}{\partial I_{H}}$ is increasing in $q$ for $0<q<\frac{1}{2}$.

Similarly, we can compute that

$$
\frac{\partial f}{\partial I_{L}}=\frac{1}{(1-2 q)^{2}}\left[(1-2 q)^{2}\left(3 q^{2}-2 q+\frac{1}{2}\right)+b^{\prime}\left(4 q^{3}-5 q^{2}+2 q-\frac{1}{2}\right)-\frac{2 b^{\prime} V_{0} B}{\Delta^{2} \eta}\right],
$$

and

$$
\frac{\partial}{\partial q}\left[(1-2 q)^{2} \frac{\partial f}{\partial I_{L}}\right]=-2(1-2 q)\left[12 q^{2}-3\left(3-\delta^{\prime}\right) q+2-\delta^{\prime}\right]<0 .
$$

So $(1-2 q)^{2} \frac{\partial f}{\partial I_{L}}$ is decreasing in $q$ for $0<q<\frac{1}{2}$.

$$
\frac{\partial f}{\partial A}=\frac{4}{\Delta \eta^{2}} \frac{\partial}{\partial q}\left[\left(1-\frac{\delta^{\prime}}{1-2 q}\right) \mathcal{V}(q)\right]
$$

Since $\left.\frac{\partial}{\partial q}\left[\left(1-\frac{\delta^{\prime}}{1-2 q}\right) \mathcal{V}(q)\right]\right|_{q=q^{*}}>0, q^{*}$ and $\beta^{*}$ are both increasing in $A$.

Proof of Implication 2: Note that $\beta=\frac{\delta}{(1-2 q) \eta}$. It is straightforward to derive that

$$
\frac{\partial}{\partial \delta}\left(\frac{\partial \beta}{\partial A}\right)=\frac{2}{(1-2 q)^{2} \eta}\left(\frac{\partial q}{\partial A}+\delta \frac{\partial}{\partial \delta}\left(\frac{\partial q}{\partial A}\right)\right)
$$

We can calculate that $\frac{\partial q}{\partial A}=\frac{X}{Y}$, where $X=\frac{4}{\left(I_{H}-I_{L}\right) \eta^{2}}\left(x_{1}-x_{2} \delta\right), Y=y_{1}+y_{2} \delta$ with $x_{1}=\left(I_{H}-I_{L}\right) \eta(1-2 q), x_{2}=\frac{\left(I_{H}-I_{L}\right) \eta(1-2 q)}{(1-2 q) \eta}+\frac{2 \mathcal{V}(q)}{(1-2 q)^{2} \eta}, y_{1}=-\frac{\partial^{2} \mathcal{V}_{F}}{\partial q^{2}}>0, y_{2}=$ $\frac{8 \mathcal{V}_{F}}{(1-2 q)^{3} \eta}+\frac{4}{(1-2 q)^{2} \eta} \frac{\partial \mathcal{V}_{F}}{\partial q}+\frac{1}{(1-2 q) \eta} \frac{\partial^{2} \mathcal{V}_{F}}{\partial q^{2}} . \mathcal{V}(q)=\left(I_{H}-I_{L}\right) \eta\left(q-q^{2}\right)+V_{0}, \mathcal{V}_{F}(q, \theta)=$ 
$-\Delta q^{3}+\left(2 I_{H}-I_{L}-B-\frac{2 c}{\eta}\right) q^{2}-\left(\frac{3}{2} I_{H}-\frac{1}{2} I_{L}-B-\frac{2 c}{\eta}\right) q+\frac{I_{H}}{2}+\frac{V_{0} B}{\Delta \eta}-\frac{c}{\eta}$. Then it is easy to check that $\frac{\partial}{\partial \delta}\left(\frac{\partial \beta}{\partial A}\right)>0$ if and only if $x_{1} y_{1}-2 x_{2} y_{1} \delta-x_{2} y_{2} \delta^{2}>0$. As $\delta$ goes to zero, due to the exsitence of feedback, the optimal $q$ goes to $q_{0}<\frac{1}{2}$. It means that $x_{1} y_{1}>0$ as $\delta$ goes to zero. So $\frac{\partial}{\partial \delta}\left(\frac{\partial \beta}{\partial A}\right)>0$ when $\delta$ is sufficiently small.

Proof of Implication 3: We show this implication using the following proposition. We will subsequently provide numerical results on monotonicity.

Proposition 3. In the optimal contract in the presence of the feedback effect, the recommended investment policy $q^{*}$ and the corresponding incentives in the contract $\beta^{*}$ have the following properties.

(i) If $A>\bar{A}$, where $\bar{A}=\frac{\Delta^{2} \eta^{2}}{8 V_{0}}\left(\frac{3 \eta}{2 b}-\frac{1}{2}\right)$, then $q^{*}$ is increasing in $I_{H}$ and decreasing in $I_{L}$, which implies that $q^{*}$ and $\beta^{*}$ are both increasing in the firm's investment opportunities $\left(I_{H}-I_{L}\right)$.

(ii) If $A<\underline{A}$, where $\underline{A}=\frac{\Delta^{2} \eta^{2}}{8 V_{0}} \frac{1}{2}\left(\frac{1}{2}-\frac{3}{2}\left(\frac{b}{\eta}\right)^{1 / 3}\right)\left(1-\left(\frac{b}{\eta}\right)^{1 / 3}\right)$, then $q^{*}$ is decreasing in $I_{H}$ and increasing in $I_{L}$, which implies that $q^{*}$ and $\beta^{*}$ are both decreasing in the firm's investment opportunities $\left(I_{H}-I_{L}\right)$.

Proof of Proposition 3: (i) Since $(1-2 q)^{2} \frac{\partial f}{\partial I_{H}}$ is increasing in $q$, if $\left.(1-2 q)^{2} \frac{\partial f}{\partial I_{H}}\right|_{q=0}>0$, then we must have $\left.(1-2 q)^{2} \frac{\partial f}{\partial I_{H}}\right|_{q=q^{*}}>0$, which implies that $\left.\frac{\partial f}{\partial I_{H}}\right|_{q=q^{*}}>0$. From the above calculations, we can see that $\left.(1-2 q)^{2} \frac{\partial f}{\partial I_{H}}\right|_{q=0}>0$ is equivalent to

$$
(1-2 q)^{2}\left(-3 q^{2}+4 q-\frac{3}{2}\right)-b^{\prime}\left(4 q^{3}-7 q^{2}+4 q-\frac{1}{2}\right)+\left.\frac{2 b^{\prime} V_{0} B}{\Delta^{2} \eta}\right|_{q=0}>0,
$$

which can be simplified to $\frac{1}{2} b^{\prime}+\frac{2 b^{\prime} V_{0} B}{\Delta^{2} \eta}>\frac{3}{2}$.

Similarly, since $(1-2 q)^{2} \frac{\partial f}{\partial I_{L}}$ is decreasing in $q$, if $\left.(1-2 q)^{2} \frac{\partial f}{\partial I_{L}}\right|_{q=0}<0$, then we must 
have $\left.(1-2 q)^{2} \frac{\partial f}{\partial I_{L}}\right|_{q=q^{*}}<0$, which implies that $\left.\frac{\partial f}{\partial I_{L}}\right|_{q=q^{*}}<0$. Also, $\left.(1-2 q)^{2} \frac{\partial f}{\partial I_{L}}\right|_{q=0}<0$ is equivalent to

$$
(1-2 q)^{2}\left(3 q^{2}-2 q+\frac{1}{2}\right)+b^{\prime}\left(4 q^{3}-5 q^{2}+2 q-\frac{1}{2}\right)-\left.\frac{2 b^{\prime} V_{0} B}{\Delta^{2} \eta}\right|_{q=0}<0,
$$

which can be simplified to $\frac{1}{2} b^{\prime}+\frac{2 b^{\prime} V_{0} B}{\Delta^{2} \eta}>\frac{1}{2}$. Therefore, as long as $\frac{1}{2} b^{\prime}+\frac{2 b^{\prime} V_{0} B}{\Delta^{2} \eta}>\frac{3}{2}$, i.e. $A>\frac{\Delta^{2} \eta^{2}}{8 V_{0}}\left(\frac{3 \eta}{2 b}-\frac{1}{2}\right)$, then $q^{*}$ is increasing in $I_{H}$ and decreasing in $I_{L}$, which implies that $q^{*}$ and $\beta^{*}$ are both increasing in the firm's opportunities $\left(I_{H}-I_{L}\right)$.

(ii) A similar argument applies here: when $A<\frac{\Delta^{2} \eta^{2}}{8 V_{0}} \frac{1}{2}\left(\frac{1}{2}-\frac{3}{2}\left(\frac{b}{\eta}\right)^{1 / 3}\right)\left(1-\left(\frac{b}{\eta}\right)^{1 / 3}\right)$, we can show that $\left.(1-2 q)^{2} \frac{\partial f}{\partial I_{H}}\right|_{q=q^{*}}<0$ and $\left.(1-2 q)^{2} \frac{\partial f}{\partial I_{L}}\right|_{q=q^{*}}>0$. Therefore, $q^{*}$ is decreasing in $I_{H}$ and increasing in $I_{L}$, which implies that $q^{*}$ and $\beta^{*}$ are both decreasing in the firm's opportunities $\left(I_{H}-I_{L}\right)$.

We have not been able to establish the monotonicity by deriving a clear sign of $\frac{\partial}{\partial A}\left(\frac{\partial \beta^{*}}{\partial\left(I_{H}-I_{L}\right)}\right)$, because both $I_{H}$ and $I_{L}$ are independent parameters and the transaction cost directly changes $\beta$ through channels independent of changes in $I_{H}$ or $I_{L}$. We have tried numerically, and have not been able to find a counterexample where the association between $\beta$ and $\left(I_{H}-I_{L}\right)$ is not monotonic in $A$. We show one set of our numerical results below for illustration purposes. The parameterization used in the following graphs is as follows: $\delta=0.05, \eta=0.5, V_{0}=1, I_{L}=1$.

\section{B Extension: Trading cost}

We now assume that it incurs a fixed cost, denoted by $c$, when the speculator chooses to trade. As the speculator trades with probability $\theta$, the expected trading cost is $c \theta$. The 
Figure 6: Numerical illustration of Implication 2

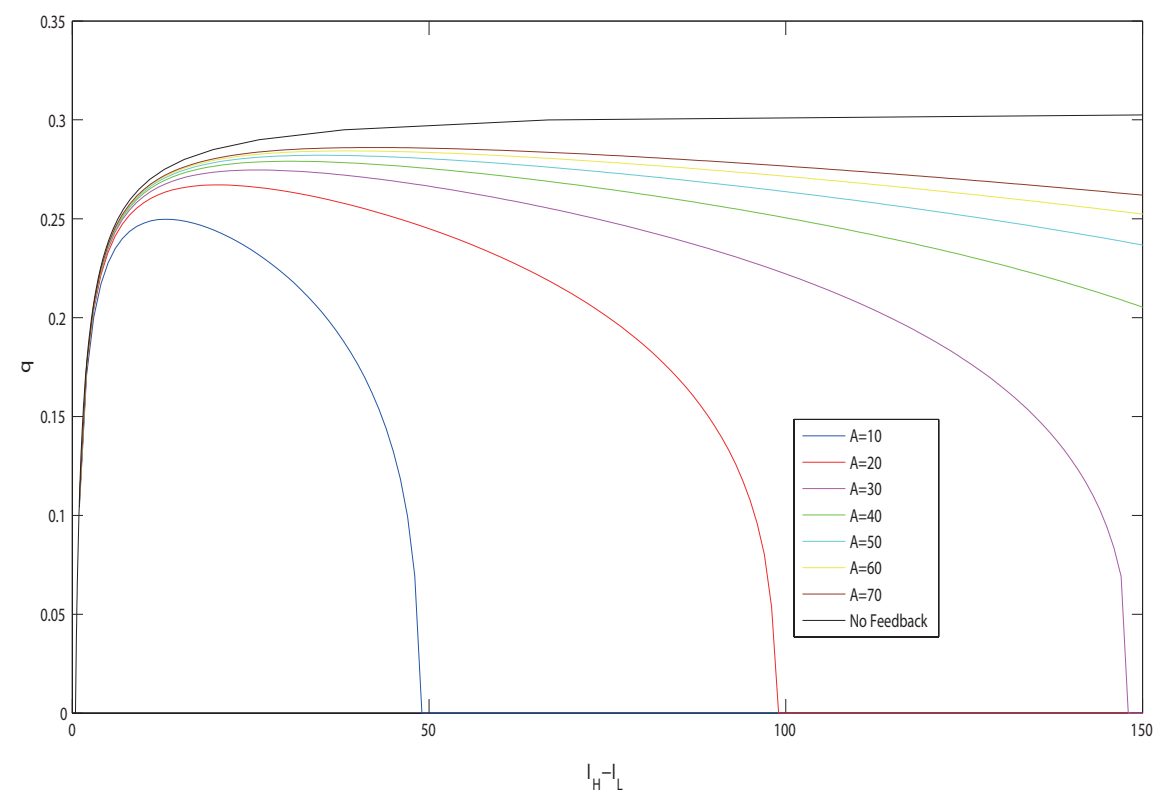

Figure 6 plots how the response of $q$ to $\left(I_{H}-I_{L}\right)$ varies with $A$.

speculator's problem is thus to maximize

$$
\max _{\theta} E \Pi-\frac{1}{2} A \theta^{2}-c \theta=\frac{\theta \eta}{2}\left(I_{H}(1-q)+I_{L} q\right)-\frac{1}{2} A \theta^{2}-c \theta .
$$

Since the market's belief of the speculator's trading strategy is that the speculator will buy on good news and sell on bad news. Thus, conditional on good news, the speculator's expected profit is $\frac{1}{2}(1-q)\left(I_{H} \eta+V_{0}-\mathcal{V}(q)\right)+\frac{1}{2} q\left(I_{L} \eta+V_{0}-\mathcal{V}(q)\right)$; conditional on bad news, the speculator's expected profit is $\frac{1}{2}(1-q)\left(\mathcal{V}(q)+I_{H} \eta-V_{0}\right)+\frac{1}{2} q\left(\mathcal{V}(q)+I_{L} \eta-V_{0}\right)$. Note that these profits lie between $\frac{\eta I_{L}}{2}$ and $\frac{\eta I_{H}}{2}$. It is straightforward to check that when $c \leq \frac{\eta I_{L}}{2}$, there is an equilibrium in which the speculator will buy on good news, and sell one share on bad news, and this is consistent with the market's belief of the speculator's trading strategy. If $c \geq \frac{\eta I_{H}}{2}$, there is an equilibrium in which the speculator will not produce information; the manager will follow his own information in this case and the stock price is set to be $\mathcal{V}(q)$. We formally state the condition for an equilibrium with information production and the contracting results below. 
Lemma 5. If $c \leq \frac{\eta I_{L}}{2}$, then there is an equilibrium in which the speculator will produce information and trade. The speculator's trading strategy is to buy one share on good news and sell one share on bad news, and this is consistent with the market's belief of the speculator's trading strategy. Moreover, the optimal amount of information production is $\theta=\frac{\eta}{2 A}\left(I_{H}(1-q)+I_{L} q-\frac{2 c}{\eta}\right)>0$. If $c \geq \frac{\eta I_{H}}{2}$, then there is an equilibrium, in which the speculator will not produce any information, and only the liquidity trader is trading in the market.

Proposition 4. In the optimal contract in the presence of the feedback effect,

I. If $c \geq \frac{\eta I_{H}}{2}$, then the speculator will not produce any information, and it conforms to the no-feedback case. As a result, $\beta^{*}=\hat{\beta}$ is increasing in the firm's investment opportunities $\left(I_{H}-I_{L}\right)$.

II. If $c \leq \frac{\eta I_{L}}{2}$, then the speculator will find it profitable to collect information and trade. The recommended investment policy satisfies $q^{*}<\hat{q}$, and thus the corresponding incentives in the contract $\beta^{*}$ are given by $\beta^{*}=\frac{\delta}{\left(1-2 q^{*}\right) \eta}<\hat{\beta}$. We also obtain the following results:

(1) $q^{*}$ and $\beta^{*}$ are both increasing in $A$ and $c$.

(2) If $A>\frac{\left(I_{H}-I_{L}\right)^{2} \eta^{2}}{8 V_{0}}\left(\frac{3 \eta}{2 \delta}-\frac{1}{2}\right)$, then $q^{*}$ is increasing in $I_{H}$ and decreasing in $I_{L}$, which implies that $q^{*}$ and $\beta^{*}$ are both increasing in the firm's investment opportunities $\left(I_{H}-\right.$ $\left.I_{L}\right)$.

(3) If $A<\frac{\left(I_{H}-I_{L}\right)^{2} \eta^{2}}{16 V_{0}}\left(\frac{1}{2}-\frac{3}{2}\left(\frac{\delta}{\eta}\right)^{1 / 3}\right)\left(1-\left(\frac{\delta}{\eta}\right)^{1 / 3}\right)$, then $q^{*}$ is decreasing in $I_{H}$ and increasing in $I_{L}$, which implies that $q^{*}$ and $\beta^{*}$ are both decreasing in the firm's investment opportunities $\left(I_{H}-I_{L}\right)$.

\section{Proof of Proposition 4:}

Proof of part (I): If $c \geq \frac{\eta I_{H}}{2}$, then $I_{H}(1-q)+I_{L} q-\frac{2 c}{\eta}<0$. So $\theta=0$. It collapses to the no-feedback case. Thus, $\beta^{*}=\hat{\beta}$ is increasing in the firm's investment opportunities $\left(I_{H}-I_{L}\right)$. 
Proof of part (II): If $c \leq \frac{\eta I_{L}}{2}$, then $I_{H}(1-q)+I_{L} q-\frac{2 c}{\eta}>0$. Thus, $\theta=\frac{\eta}{2 A}\left(I_{H}(1-q)+I_{L} q-\frac{2 c}{\eta}\right)>$ 0 . For simplicity, we define $\delta^{\prime}=\delta / \eta$, then $\beta=\frac{\delta}{(1-2 q) \eta}=\frac{\delta^{\prime}}{1-2 q}$. Also, $0<\beta<1$ implies that $0<\delta^{\prime}<1$. The shareholders' objective is to maximize $(1-\beta) \mathcal{V}_{F}(q, \theta)$, where $0<\beta=$ $\frac{\delta^{\prime}}{1-2 q}<1$. Note that $\frac{\partial}{\partial q}\left[\left(1-\frac{\delta^{\prime}}{1-2 q}\right) \mathcal{V}(q)\right]=\Delta \eta\left[1-2 q-\delta^{\prime}-\frac{2 \delta^{\prime}\left(q-q^{2}\right)}{(1-2 q)^{2}}-\frac{2 \delta^{\prime} V_{0}}{\eta \Delta(1-2 q)^{2}}\right]$, which is decreasing in $q$ for $q<\frac{1}{2}$. So for any $\frac{1}{2}>q \geq \hat{q}, \frac{\partial}{\partial q}\left[\left(1-\frac{\delta^{\prime}}{1-2 q}\right) \mathcal{V}(q)\right] \leq 0$. Hence, for any $\frac{1}{2}>q \geq \hat{q}, \frac{\partial}{\partial q}\left[\left(1-\frac{\delta^{\prime}}{1-2 q}\right) \mathcal{V}_{F}\right] \leq \frac{\partial}{\partial q}\left[\left(1-\frac{\delta^{\prime}}{1-2 q}\right) \frac{\theta \Delta \eta}{2}\left(\frac{1}{2}-q+q^{2}\right)\right]<$ 0 holds. So $q^{*}<\hat{q}$. Thus, $\beta^{*}=\frac{\delta^{\prime}}{\left(1-2 q^{*}\right) \eta}<\hat{\beta}$.

Plugging $\theta=\frac{\eta}{2 A}\left(I_{H}(1-q)+I_{L} q-\frac{2 c}{\eta}\right)$ into $\mathcal{V}_{F}(q, \theta)$ yields that maximizing $\left(1-\frac{\delta^{\prime}}{1-2 q}\right) \mathcal{V}_{F}(q, \theta)$ is equivalent to maximizing

$$
\begin{aligned}
& F(q, x)=\left(1-\frac{\delta^{\prime}}{1-2 q}\right) \times \\
& {\left[-\Delta q^{3}+\left(2 I_{H}-I_{L}-B-\frac{2 c}{\eta}\right) q^{2}-\left(\frac{3}{2} I_{H}-\frac{1}{2} I_{L}-B-\frac{2 c}{\eta}\right) q+\frac{I_{H}}{2}+\frac{V_{0} B}{\Delta \eta}-\frac{c}{\eta}\right],}
\end{aligned}
$$

where $B=\frac{4 A}{\eta}$. Denote $f(q, x)=\frac{\partial F}{\partial q}$, where $x$ refers to the parameter $I_{H} I_{L}, c$, or $A$. Then we have $\frac{\partial f}{\partial x}+\frac{\partial f}{\partial q} \frac{\partial q}{\partial x}=0$. Since at the maximum $q^{*}$, we must have $\frac{\partial f}{\partial q}<0$, the sign of $\frac{\partial q}{\partial x}$ is the same as the sign of $\frac{\partial f}{\partial x}$.

Proof of part (1) of (II): $\frac{\partial f}{\partial A}=\frac{\partial}{\partial q}\left(\frac{\partial F}{\partial A}\right)=\frac{4}{\Delta \eta^{2}} \frac{\partial}{\partial q}\left[\left(1-\frac{\delta^{\prime}}{1-2 q}\right) \mathcal{V}(q)\right]$. Note that $\left.\frac{\partial}{\partial q}\left[\left(1-\frac{\delta^{\prime}}{1-2 q}\right) \mathcal{V}(q)\right]\right|_{q=\hat{q}}=0, \frac{\partial}{\partial q}\left[\left(1-\frac{\delta^{\prime}}{1-2 q}\right) \mathcal{V}(q)\right]$ is decreasing in $q$, and $q^{*}<\hat{q}$, so $\left.\frac{\partial}{\partial q}\left[\left(1-\frac{\delta^{\prime}}{1-2 q}\right) \mathcal{V}(q)\right]\right|_{q=q^{*}}>0$. Thus, $q^{*}$ and $\beta^{*}$ are both increasing in $A$.

$$
\frac{\partial f}{\partial c}=\frac{\partial}{\partial q}\left(\frac{\partial F}{\partial c}\right)=\frac{2}{\eta}\left(\frac{2 \delta^{\prime}}{(1-2 q)^{2}}\left(\frac{1}{2}-q+q^{2}\right)+\left(1-\frac{\delta^{\prime}}{1-2 q}\right)(1-2 q)\right)>0 .
$$


So $q^{*}$ and $\beta^{*}$ are both increasing in $c$.

Proof of part (2) of (II): We first compute that

$$
\begin{aligned}
\frac{\partial f}{\partial I_{H}} & =\frac{\partial}{\partial q}\left(\frac{\partial F}{\partial I_{H}}\right) \\
& =\frac{1}{(1-2 q)^{2}}\left[(1-2 q)^{2}\left(-3 q^{2}+4 q-\frac{3}{2}\right)-\delta^{\prime}\left(4 q^{3}-7 q^{2}+4 q-\frac{1}{2}\right)+\frac{2 \delta^{\prime} V_{0} B}{\Delta^{2} \eta}\right] .
\end{aligned}
$$

We can obtain that

$$
\frac{\partial}{\partial q}\left[(1-2 q)^{2} \frac{\partial f}{\partial I_{H}}\right]=(1-2 q)\left[-4\left(-3 q^{2}+4 q-\frac{3}{2}\right)+\left(1-2 q-\delta^{\prime}\right)(4-6 q)\right]>0
$$

Thus, $(1-2 q)^{2} \frac{\partial f}{\partial I_{H}}$ is increasing in $q$ for $0<q<\frac{1}{2}$.

Similarly, we can compute that

$$
\frac{\partial f}{\partial I_{L}}=\frac{1}{(1-2 q)^{2}}\left[(1-2 q)^{2}\left(3 q^{2}-2 q+\frac{1}{2}\right)+\delta^{\prime}\left(4 q^{3}-5 q^{2}+2 q-\frac{1}{2}\right)-\frac{2 \delta^{\prime} V_{0} B}{\Delta^{2} \eta}\right]
$$

and

$$
\frac{\partial}{\partial q}\left[(1-2 q)^{2} \frac{\partial f}{\partial I_{L}}\right]=-2(1-2 q)\left[12 q^{2}-3\left(3-\delta^{\prime}\right) q+2-\delta^{\prime}\right]<0
$$

Thus, $(1-2 q)^{2} \frac{\partial f}{\partial I_{L}}$ is decreasing in $q$ for $0<q<\frac{1}{2}$.

Since $(1-2 q)^{2} \frac{\partial f}{\partial I_{H}}$ is increasing in $q$, if $\left.(1-2 q)^{2} \frac{\partial f}{\partial I_{H}}\right|_{q=0}>0$, then we must have $\left.(1-2 q)^{2} \frac{\partial f}{\partial I_{H}}\right|_{q=q^{*}}>0$, which implies that $\left.\frac{\partial f}{\partial I_{H}}\right|_{q=q^{*}}>0$. From the above calculations, we can see that $\left.(1-2 q)^{2} \frac{\partial f}{\partial I_{H}}\right|_{q=0}>0$ is equivalent to

$$
(1-2 q)^{2}\left(-3 q^{2}+4 q-\frac{3}{2}\right)-\delta^{\prime}\left(4 q^{3}-7 q^{2}+4 q-\frac{1}{2}\right)+\left.\frac{2 \delta^{\prime} V_{0} B}{\Delta^{2} \eta}\right|_{q=0}>0,
$$


which can be simplified to $\frac{1}{2} \delta^{\prime}+\frac{2 \delta^{\prime} V_{0} B}{\Delta^{2} \eta}>\frac{3}{2}$.

Similarly, since $(1-2 q)^{2} \frac{\partial f}{\partial I_{L}}$ is decreasing in $q$, if $\left.(1-2 q)^{2} \frac{\partial f}{\partial I_{L}}\right|_{q=0}<0$, then we must have $\left.(1-2 q)^{2} \frac{\partial f}{\partial I_{L}}\right|_{q=q^{*}}<0$, which implies that $\left.\frac{\partial f}{\partial I_{L}}\right|_{q=q^{*}}<0$. Also $\left.(1-2 q)^{2} \frac{\partial f}{\partial I_{L}}\right|_{q=0}<0$ is equivalent to

$$
(1-2 q)^{2}\left(3 q^{2}-2 q+\frac{1}{2}\right)+\delta^{\prime}\left(4 q^{3}-5 q^{2}+2 q-\frac{1}{2}\right)-\left.\frac{2 \delta^{\prime} V_{0} B}{\Delta^{2} \eta}\right|_{q=0}<0
$$

which can be simplified to $\frac{1}{2} \delta^{\prime}+\frac{2 \delta^{\prime} V_{0} B}{\Delta^{2} \eta}>\frac{1}{2}$. Therefore, as long as $\frac{1}{2} \delta^{\prime}+\frac{2 \delta^{\prime} V_{0} B}{\Delta^{2} \eta}>\frac{3}{2}$, i.e., $A>\frac{\Delta^{2} \eta^{2}}{8 V_{0}}\left(\frac{3 \eta}{2 \delta}-\frac{1}{2}\right)$, then $q^{*}$ is increasing in $I_{H}$ and decreasing in $I_{L}$, which implies that $q^{*}$ and $\beta^{*}$ are both increasing in the firm's opportunities $\left(I_{H}-I_{L}\right)$.

Proof of part (3) of (II): A similar argument applies here: when the following holds

$$
A<\frac{\Delta^{2} \eta^{2}}{8 V_{0}} \frac{1}{2}\left(\frac{1}{2}-\frac{3}{2}\left(\frac{\delta}{\eta}\right)^{1 / 3}\right)\left(1-\left(\frac{\delta}{\eta}\right)^{1 / 3}\right)
$$

we can show that $\left.(1-2 q)^{2} \frac{\partial f}{\partial I_{H}}\right|_{q=q^{*}}<0$ and $\left.(1-2 q)^{2} \frac{\partial f}{\partial I_{L}}\right|_{q=q^{*}}>0$. Therefore, $q^{*}$ is decreasing in $I_{H}$ and increasing in $I_{L}$, which implies that $q^{*}$ and $\beta^{*}$ are both decreasing in the firm's opportunities $\left(I_{H}-I_{L}\right)$. 
Table 1. The effects of Reg SHO and decimalization on WPS

This table presents the effects of Reg SHO and decimalization on WPS. In columns (1) and (2), we examine the impact of Reg SHO on WPS. The sample is from $2001 \mathrm{tp} 2007 . I^{P I L O T}$ is a dummy variable indicating firms that are selected as Reg SHO treated stock, and zero for the remaining firms in the Russell 3000 index. $I^{\text {During }}$ is a time dummy that equals one from 2005 to 2007 , and zero for time during 2001 to 2003 . We exclude the year of 2004, as it is the year when the SEC announced the pilot program. In columns (3) and (4), we examine the impact of decimalization on WPS. I ${ }^{\text {Decimal }}$ is a dummy variable that equals 1 for the period after 2001. WPS measures the wealth-performance sensitivities, which is the dollar change in CEO wealth for a 100 percentage point change in firm value, divided by annual flow compensation (Edmans et al. (2009)). Tobin's Q is the ratio of the market value of assets to the book value of assets, where the market value of assets is defined as the book value of assets (data 6) plus the market value of common equity (data 25 times data 199) less the book value of common equity (data 60) and balance sheet deferred taxes (data 74). Size is the logarithm of total asset. Leverage is the sum of short-term debt (data 34) and long-term debt (data 9) divided by the sum of short-term and long-term debt and stockholders equity (data 216). Dividend is a dummy variable equal to one if a firm distributes dividends this year and zero otherwise. Age is calculated based on the first time when the firm's accounting information appeared in Compustat. IOR is the institutional investors' ownership ratio. Cash is the ratio of cash (data 126) divided by total assets (data 6). INV is the investment-to-capital ratio (INV), which is capital expenditure (data 128) divided by fixed assets (data 8). IOC is the measure for concentration of institutional ownership, which is the sum of the top five institutional investors that share ownership. RetStd is proxied for risk, which is calculated as the standard deviation of monthly stock returns. All regressions are controlled for firm and year fixed effects. Standard errors are clustered at year level and reported in the parenthesis. *, **, and *** represent statistical significance at the $10 \%, 5 \%$, and $1 \%$ level, respectively.

\begin{tabular}{|c|c|c|c|c|}
\hline & (1) PILOT & (2) PILOT & (3) DECIMAL & (4) DECIMAL \\
\hline$I^{P I L O T} \times I^{\text {During }}$ & $\begin{array}{r}-0.139 * * \\
(0.052)\end{array}$ & $\begin{array}{r}-0.195 * * * \\
(0.053)\end{array}$ & & \\
\hline$I^{\text {Decimal }}$ & & & $\begin{array}{r}-0.202^{* * * *} \\
(0.030)\end{array}$ & $\begin{array}{r}-0.084^{* * *} \\
(0.020)\end{array}$ \\
\hline Size & & $\begin{array}{r}0.095 \\
(0.090)\end{array}$ & & $\begin{array}{r}0.153^{* * *} \\
(0.019)\end{array}$ \\
\hline Tobin's Q & & $\begin{array}{r}0.046^{* *} \\
(0.016)\end{array}$ & & $\begin{array}{r}0.145^{* * *} \\
(0.021)\end{array}$ \\
\hline Leverage & & $\begin{array}{r}-0.060 \\
(0.119)\end{array}$ & & $\begin{array}{r}-0.046 \\
(0.083)\end{array}$ \\
\hline Dividend & & $\begin{array}{r}-0.052 \\
(0.075)\end{array}$ & & $\begin{array}{r}-0.125^{* * *} \\
(0.023)\end{array}$ \\
\hline Age & & $\begin{array}{r}-0.089 \\
(0.103)\end{array}$ & & $\begin{array}{r}-0.206^{* * *} \\
(0.038)\end{array}$ \\
\hline IOR & & $\begin{array}{r}-0.009 \\
(0.090)\end{array}$ & & $\begin{array}{r}-0.159^{* *} \\
(0.060)\end{array}$ \\
\hline Cash & & $\begin{array}{r}0.056 \\
(0.497)\end{array}$ & & $\begin{array}{r}0.025 \\
(0.093)\end{array}$ \\
\hline INV & & $\begin{array}{r}0.128 \\
(0.124)\end{array}$ & & $\begin{array}{l}0.093^{*} \\
(0.049)\end{array}$ \\
\hline $\mathrm{IOC}$ & & $\begin{array}{r}-0.500 \\
(0.349)\end{array}$ & & $\begin{array}{r}-0.325^{*} \\
(0.178)\end{array}$ \\
\hline RetStd & & $\begin{array}{r}-0.115 \\
(0.617)\end{array}$ & & $\begin{array}{r}0.032 \\
(0.112)\end{array}$ \\
\hline Year Dummies & $\mathrm{Y}$ & $\mathrm{Y}$ & $\mathrm{N}$ & $\mathrm{N}$ \\
\hline Firm Dummies & $\mathrm{Y}$ & $\mathrm{Y}$ & $\mathrm{Y}$ & $\mathrm{Y}$ \\
\hline No. of Obs & 6259 & 5687 & 25902 & 25571 \\
\hline R-squared & 0.6830 & 0.7048 & 0.5805 & 0.5958 \\
\hline
\end{tabular}


Table 2. The impact of MTEB on the negative association between PILOT and WPS

This table examines the impact of Managerial Tendencies for Empire-Building (MTEB) on the negative association between Reg SHO and managerial compensation (WPS). The sample is from 2001 to 2007. I ILOT is a dummy variable indicating firms that are selected as Reg SHO treated stock, and zero for the remaining firms in the Russell 3000 index. $I^{\text {During }}$ is a time dummy that equals one from 2005 to 2007, and zero during 2001 to 2003 . We exclude the year of 2004, as it is the year when the SEC announced the pilot program. In column (1), MTEB1 represents negative New KZ index (Hadlock and Pierce (2010)). In column (2), we use negative Kaplan-Zingales index (Kaplan and Zingales (1997)) to proxy for MTEB2. In column (3), MTEB3 represents negative HP index (Hadlock and Pierce (2010)). In column (4), we use negative firms' leverage ratio to proxy for MTEB4. WPS measures the wealth-performance sensitivities, which is the dollar change in CEO wealth for a 100 percentage point change in firm value, divided by annual flow compensation (Edmans et al. (2009)). Tobin's Q is the ratio of the market value of assets to the book value of assets, where the market value of assets is defined as the book value of assets (data 6) plus the market value of common equity (data 25 times data 199) less the book value of common equity (data 60) and balance sheet deferred taxes (data 74). Size is the logarithm of total assets. Leverage is the sum of short-term debt (data 34) and long-term debt (data 9) divided by the sum of short-term and long-term debt and stockholders equity (data 216). Dividend is a dummy variable equal to one if a firm distributes dividends in this year and zero otherwise. Age is calculated based on the first time when the firm's accounting information appeared in Compustat. IOR is the institutional investors' ownership ratio. Cash is the ratio of cash (data 126) divided by total assets (data 6). INV is the investment-to-capital ratio (INV), which is capital expenditure (data 128) divided by fixed assets (data 8). IOC is the measure for concentration of institutional ownership, which is the sum of the top five institutional investors that share ownership. RetStd is proxied for risk, which is calculated as the standard deviation of monthly stock returns. All regressions are controlled for firm and year fixed effects. Standard errors are clustered at year level and reported in the parenthesis. *, **, and *** represent statistical significance at the $10 \%, 5 \%$, and $1 \%$ level, respectively.

\begin{tabular}{|c|c|c|c|c|}
\hline & & Depende & le: WPS & \\
\hline & (1) MTEB1 & (2) MTEB2 & (3) MTEB3 & (4) MTEB4 \\
\hline MTEB $\times I^{\text {PILOT }} \times I^{\text {During }}$ & $-0.026^{* *}$ & $-0.224^{* * *}$ & -0.028 & $-1.160^{* *}$ \\
\hline \multirow{2}{*}{$I^{\text {PILOT }} \times I^{\text {During }}$} & $\begin{array}{r}(0.007) \\
-0.103^{*}\end{array}$ & $\begin{array}{r}(0.052) \\
-0.351^{* * *}\end{array}$ & $\begin{array}{r}(0.022) \\
0.028\end{array}$ & $\begin{array}{r}(0.332) \\
-0.442^{* *}\end{array}$ \\
\hline & $(0.046)$ & $(0.041)$ & $(0.212)$ & $(0.114)$ \\
\hline \multirow[t]{2}{*}{$\mathrm{MTEB} \times I^{P I L O T}$} & $0.029^{*}$ & $0.100^{*}$ & 0.045 & $0.731^{* *}$ \\
\hline & $(0.014)$ & $(0.039)$ & $(0.029)$ & $(0.257)$ \\
\hline \multirow[t]{2}{*}{ MTEB $\times I^{\text {During }}$} & 0.004 & -0.034 & 0.025 & 0.042 \\
\hline & $(0.003)$ & $(0.068)$ & $(0.012)$ & $(0.241)$ \\
\hline \multirow[t]{2}{*}{ Size } & 0.085 & 0.088 & 0.172 & 0.091 \\
\hline & $(0.081)$ & $(0.066)$ & $(0.198)$ & $(0.082)$ \\
\hline \multirow[t]{2}{*}{ Tobin's Q } & $0.047^{* *}$ & $0.059^{* *}$ & $0.046^{* *}$ & $0.046^{* *}$ \\
\hline & $(0.018)$ & $(0.022)$ & $(0.017)$ & $(0.016)$ \\
\hline \multirow[t]{2}{*}{ Leverage } & -0.000 & -0.079 & -0.023 & \\
\hline & $(0.186)$ & $(0.118)$ & $(0.159)$ & \\
\hline \multirow[t]{2}{*}{ Dividend } & -0.054 & -0.036 & -0.048 & -0.035 \\
\hline & $(0.073)$ & $(0.047)$ & $(0.078)$ & (0.098) \\
\hline \multirow[t]{2}{*}{ Age } & -0.065 & -0.060 & -0.020 & -0.025 \\
\hline & $(0.098)$ & $(0.102)$ & $(0.108)$ & $(0.074)$ \\
\hline \multirow[t]{2}{*}{ IOR } & -0.013 & -0.070 & 0.045 & 0.069 \\
\hline & $(0.070)$ & $(0.082)$ & $(0.053)$ & $(0.344)$ \\
\hline \multirow[t]{2}{*}{ Cash } & -0.059 & -0.173 & 0.053 & 0.170 \\
\hline & $(0.334)$ & $(0.103)$ & $(0.340)$ & $(0.089)$ \\
\hline \multirow[t]{2}{*}{ INV } & 0.163 & 0.085 & 0.124 & $-0.512^{*}$ \\
\hline & $(0.114)$ & $(0.112)$ & $(0.084)$ & $(0.214)$ \\
\hline \multirow[t]{2}{*}{ IOC } & -0.529 & -0.272 & -0.571 & 0.011 \\
\hline & $(0.288)$ & $(0.225)$ & $(0.287)$ & $(0.851)$ \\
\hline \multirow[t]{2}{*}{ RetStd } & -0.014 & -0.193 & -0.146 & -0.081 \\
\hline & $(0.858)$ & $(0.695)$ & $(0.849)$ & $(0.127)$ \\
\hline \multirow[t]{2}{*}{ MTEB } & -0.004 & 0.002 & -0.095 & -0.056 \\
\hline & $(0.004)$ & $(0.076)$ & $(0.120)$ & $(0.078)$ \\
\hline Year dummies & $\mathrm{Y}$ & $\mathrm{Y}$ & $\mathrm{Y}$ & Y \\
\hline Firm dummies & $\mathrm{Y}$ & $\mathrm{Y}$ & $\mathrm{Y}$ & $\mathrm{Y}$ \\
\hline No. of Obs. & 5747 & 5748 & 5687 & 5686 \\
\hline R-squared & 0.7040 & 0.7387 & 0.7051 & 0.7055 \\
\hline
\end{tabular}


Table 3. The impact of MTEBs on the negative association between decimalization and WPS

This table examines the impact of Managerial Tendencies for Empire-Building (MTEB) on the negative association between decimalization and managerial compensation (WPS). $I^{\text {Decimal }}$ is a dummy variable that equals 1 for the period after 2001. In column (1), MTEB1 represents negative New KZ index (Hadlock and Pierce (2010)). In column (2), we use negative KaplanZingales index (Kaplan and Zingales (1997)) to proxy for MTEB2. In column (3), MTEB3 represents negative HP index (Hadlock and Pierce (2010)). In column (4), we use negative firms' leverage ratio to proxy for MTEB4. WPS measures the wealth-performance sensitivities, which is the dollar change in CEO wealth for a 100 percentage point change in firm value, divided by annual flow compensation (Edmans et al. (2009)). Tobin's $Q$ is the ratio of the market value of assets to the book value of assets, where the market value of assets is defined as the book value of assets (data 6) plus the market value of common equity (data 25 times data 199) less the book value of common equity (data 60) and balance sheet deferred taxes (data 74). Size is the logarithm of total assets. Leverage is the sum of short-term debt (data 34) and long-term debt (data 9) divided by the sum of short-term and long-term debt and stockholders equity (data 216). Dividend is a dummy variable equal to one if a firm distributes dividends in this year and zero otherwise. Age is calculated based on the first time when the firm's accounting information appeared in Compustat. IOR is the institutional investors' ownership ratio. Cash is the ratio of cash (data 126) divided by total assets (data 6). INV is the investment-to-capital ratio (INV), which is capital expenditure (data 128) divided by fixed assets (data 8). IOC is the measure for concentration of institutional ownership, which is the sum of the top five institutional investors that share ownership. RetStd is proxied for risk, which is calculated as the standard deviation of monthly stock returns. All regressions are controlled for firm and year fixed effects. Standard errors are clustered at year level and reported in parentheses. ${ }^{*}, * *$, and ${ }^{* *}$ represent statistical significance at the $10 \%, 5 \%$, and $1 \%$ level, respectively.

\begin{tabular}{|c|c|c|c|c|}
\hline & \multicolumn{4}{|c|}{ Dependent variable: WPS } \\
\hline & (1) MTEB1 & (2) MTEB2 & (3) MTEB3 & (4) MTEB4 \\
\hline \multirow[t]{2}{*}{ MTEB $\times I^{\text {Decimal }}$} & $-0.075^{* *}$ & $-0.004 *$ & $-0.028^{* * *}$ & $-0.305^{* *}$ \\
\hline & $(0.029)$ & $(0.002)$ & $(0.008)$ & $(0.132)$ \\
\hline \multirow[t]{2}{*}{ Size } & $0.166^{* * *}$ & $0.168^{* * *}$ & $0.217^{* * *}$ & $0.173^{* * *}$ \\
\hline & $(0.020)$ & $(0.025)$ & $(0.030)$ & $(0.025)$ \\
\hline \multirow[t]{2}{*}{ Tobin's Q } & $0.144^{* * *}$ & $0.147^{* * *}$ & $0.150^{* * *}$ & $0.146^{* * *}$ \\
\hline & $(0.022)$ & $(0.023)$ & $(0.022)$ & $(0.023)$ \\
\hline \multirow[t]{2}{*}{ Leverage } & -0.061 & -0.078 & -0.060 & \\
\hline & $(0.215)$ & $(0.090)$ & $(0.092)$ & \\
\hline \multirow[t]{2}{*}{ Dividend } & $-0.124^{* * *}$ & $-0.130^{* * *}$ & $-0.107^{* * *}$ & $-0.120^{* * *}$ \\
\hline & $(0.024)$ & $(0.026)$ & $(0.022)$ & $(0.025)$ \\
\hline \multirow[t]{2}{*}{ Age } & $-0.158^{* * *}$ & $-0.163^{* * *}$ & $-0.197^{* * *}$ & $-0.161^{* * *}$ \\
\hline & $(0.038)$ & $(0.038)$ & $(0.050)$ & $(0.039)$ \\
\hline \multirow[t]{2}{*}{ IOR } & $-0.119^{*}$ & $-0.133^{* *}$ & $-0.173^{* *}$ & $-0.138^{* *}$ \\
\hline & $(0.059)$ & $(0.061)$ & $(0.071)$ & $(0.061)$ \\
\hline \multirow[t]{2}{*}{ Cash } & 0.067 & -0.016 & 0.080 & 0.056 \\
\hline & $(0.092)$ & $(0.106)$ & $(0.102)$ & $(0.093)$ \\
\hline \multirow[t]{2}{*}{ INV } & 0.046 & 0.024 & 0.066 & 0.046 \\
\hline & $(0.047)$ & $(0.061)$ & $(0.049)$ & $(0.047)$ \\
\hline \multirow[t]{2}{*}{ IOC } & $-0.342^{*}$ & $-0.263^{* *}$ & -0.174 & $-0.256^{* *}$ \\
\hline & $(0.166)$ & $(0.108)$ & $(0.104)$ & $(0.106)$ \\
\hline \multirow[t]{2}{*}{ RetStd } & 0.138 & 0.244 & 0.281 & 0.218 \\
\hline & $(0.147)$ & $(0.172)$ & $(0.166)$ & $(0.187)$ \\
\hline \multirow[t]{2}{*}{ MTEB } & 0.042 & $0.004^{*}$ & -0.016 & $0.237^{*}$ \\
\hline & $(0.060)$ & $(0.002)$ & $(0.025)$ & $(0.117)$ \\
\hline Year Dummies & $\mathrm{Y}$ & $\mathrm{Y}$ & Y & $\mathrm{Y}$ \\
\hline Firm Dummies & Y & Y & $\mathrm{Y}$ & $\mathrm{Y}$ \\
\hline No. of Obs & 25569 & 25569 & 25571 & 25571 \\
\hline $\mathrm{R}$-squared & 0.5933 & 0.5933 & 0.5871 & 0.5932 \\
\hline
\end{tabular}


Table 4. The mitigation effect of the Reg SHO and decimalization on the positive relation between Tobin's $\mathrm{Q}$ and WPS

This table presents the mitigation effect of Reg SHO and decimalization on the positive relation between Tobin's Q and WPS. In columns (1) and (2), we examine the impact of the Reg-SHO program on positive association between Tobin's Q and WPS. The sample is from 2001 to $2007 . I^{P I L O T}$ is a dummy variable indicating firms that are selected as the Reg SHO treated stocks, and zero for the rest of the firms in the Russell 3000 index. $I^{\text {During }}$ is a time dummy that equals one from 2005 to 2007 , and zero during 2001 to 2003 . We exclude the year of 2004, as this year is when the SEC announced the pilot program. IDecimal is a dummy variable that equals 1 for the period after 2001. WPS measures the wealth-performance sensitivities, which is the dollar change in $\mathrm{CEO}$ wealth for a 100 percentage point change in firm value, divided by annual flow compensation (Edmans et al. (2009)). Tobin's Q is the ratio of the market value of assets to the book value of assets, where the market value of assets is defined as the book value of assets (data 6) plus the market value of common equity (data 25 times data 199) less the book value of common equity (data 60) and balance sheet deferred taxes (data 74). Size is the logarithm of total assets. Leverage is the sum of short-term debt (data 34) and long-term debt (data 9) divided by the sum of short-term and long-term debt and stockholders' equity (data 216). Dividend is a dummy variable equal to one when a firm distributes dividends this year, and zero otherwise. Age is calculated based on the first time when firm's accounting information appeared in Compustat. IOR is the institutional investors' ownership ratio. Cash is the ratio of cash (data 126) divided by total asset (data 6). INV is the investment-to-capital ratio (INV), which is capital expenditure (data 128) divided by fixed assets (data 8). IOC is the measure for concentration of institutional ownership, which is the sum of the top five institutional investors that share ownership. RetStd is proxied for risk, which is calculated as the standard deviation of monthly stock returns. All regressions are controlled for firm and year fixed effect. Standard errors are clustered at year level and reported in the parenthesis. *, **, and *** represent statistical significance at the $10 \%, 5 \%$, and $1 \%$ level, respectively.

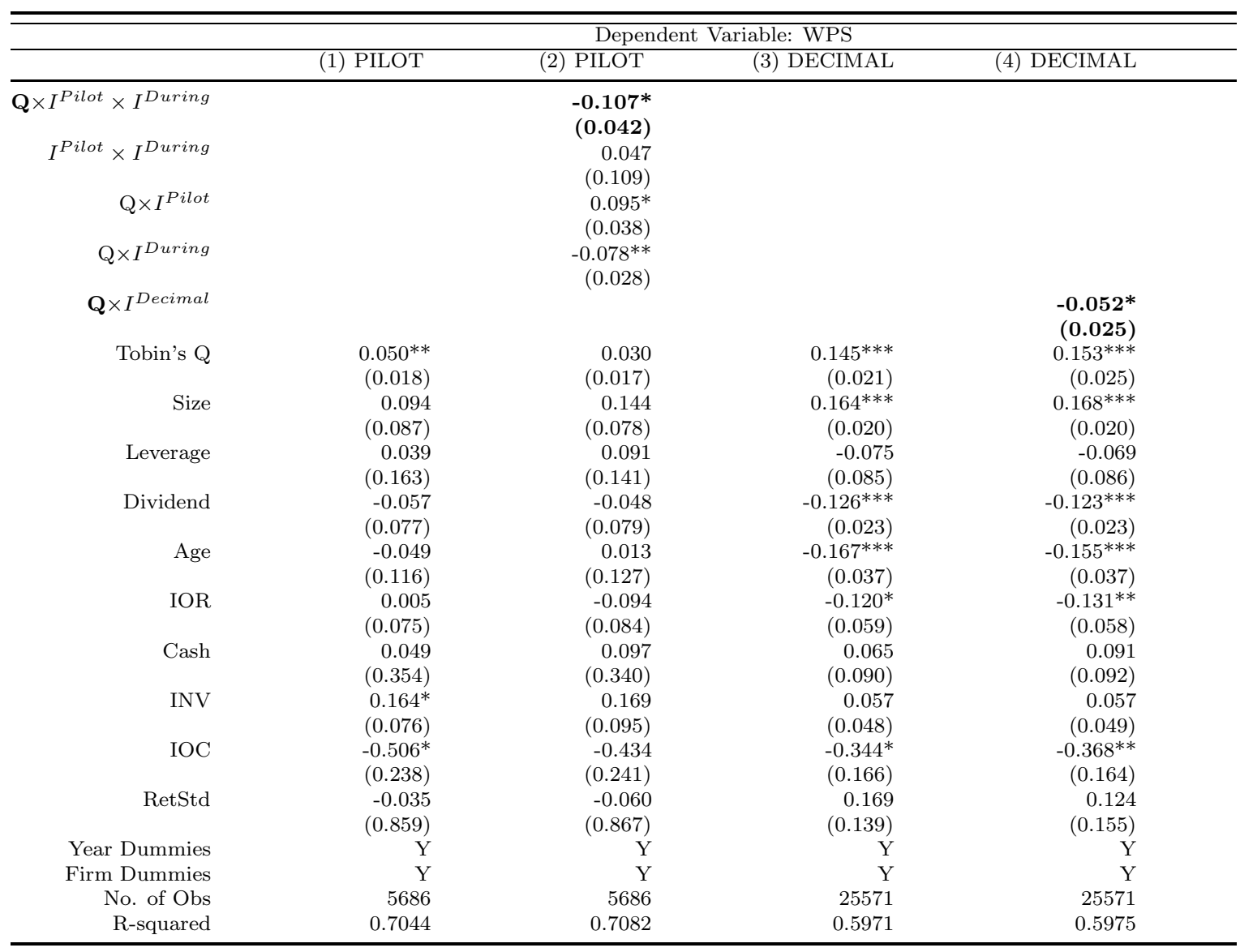




\section{References}

Aggarwal, R. K., and A. A. Samwick. 2006. Empire-builders and shirkers: investment, firm performance, and managerial incentives. Journal of Corporate Finance, 12. Corporate Governance: 489515 .

Alexander, G. J., Peterson, M. A. 2008. The effect of price tests on trader behavior and market quality: An analysis of reg SHO. Journal of Financial Markets, 11(1), 84-111.

Allen, F., A. Chakraborty, and B. Chowdhry. 2012. Why Is CEO compensation excessive and unrelated to their performance? Working paper.

Baker M, Stein JC, Wurgler J. 2003. When does the market matter? Stock prices and the investment of equity-dependent firms. Quarterly Journal of Economics, 118(3), 969-1006.

Bakke TE, Whited T. M., 2010. Which firms follow the market? An analysis of corporate investment decisions. Review of Financial Studies, 23(5), 1941-1980.

Baldenius, T. 2003. Delegated investment decisions and private benefits of control. The Accounting Review, 78:909930.

Baldenius, T., N. Melumad, and X. Meng. 2014. Board composition and CEO power. Journal of Financial Economics, 112:5368.

Baumol, W. J. 1959. Business behavior, value and growth. Vol. 1967 New York.

Bertrand, M., and Mullainathan, S. 2003. Enjoying the quiet life? Corporate governance and managerial preferences. Journal of Political Economy, 111(5), 1043-1075.

Bessembinder, H. 2003. Trade execution costs and market quality after decimalization. Journal of Financial and Quantitative Analysis, 38(4), 747-777.

Bharath, S. T., Jayaraman, S., Nagar, V. 2013. Exit as governance: An empirical analysis. Journal of Finance, 68(6), 2515-2547.

Billett, M. T., J. A. Garfinkel, and Y. Jiang. 2011. The influence of governance on investment: evidence from a hazard Model. Journal of Financial Economics, 102:64370. 
Bizjak, J. M., J. A. Brickley, and J. L. Coles. 1993. Stock-based incentive compensation and investment behavior. Journal of Accounting and Economics, 16:34972.

Bond P, Edmans A., Goldstein I. 2012. The real effects of financial markets. Annual Review of Financial Economics, 4, 339-360.

Bond, P., Goldstein, I., and E. S. Prescott, 2010. Market-based corrective actions. Review of Financial Studies, 23, 782-820.

Chang, C. 1993. Payout policy, capital structure, and compensation contracts when managers value control. Review of Financial Studies, 6:91133.

Chang, C., X. Yu. 2010. Informational efficiency and liquidity premium as the determinants of capital structure. Journal of Financial and Quantitative Analysis, 401-440.

Chen Q, Goldstein I, Jiang W. 2007. Price informativeness and investment sensitivity to stock price. Review of Financial Studies, 20(3), 619-650.

Diether K. B., Lee K. H., Werner I.M. 2009. Short-sale strategies and return predictability. Review of Financial Studies, 22(2), 575-607.

D. W. Diamond and R.E. Verrecchia. 1982. Optimal managerial contracts and equilibrium security prices. Journal of Finance 37.2 , 275-287.

Dow J, Goldstein I, Guembel A. 2011. Incentives for information production in markets where prices affect real investment. Working Paper.

Edmans A, Gabaix X, Landier A. 2009. A multiplicative model of optimal CEO incentives in market equilibrium. Review of Financial Studies, 22(12), 4881-4917.

Edmans, A., Goldstein, I., Jiang, W. 2012. The real effects of financial markets: The impact of prices on takeovers. Journal of Finance, 67(3), 933-971.

Edmans, A., Goldstein, I., Jiang, W. 2015. Feedback effects, asymmetric trading, and the limits to arbitrage. Forthcoming in the American Economic Review.

Eisfeldt, A. L., and A. A. Rampini. 2008. Managerial incentives, capital reallocation, 
and the Business cycle. Journal of Financial Economics, 87:17799.

Fang VW, Noe TH, Tice S. 2009. Stock market liquidity and firm Value. Journal of Financial Economics, 94(1), 150-169.

Fang, V. W., Huang, A., and Karpoff, J. M. 2014. Short selling and earnings management: A controlled experiment. Available at SSRN 2286818.

Fishman M. J., Hagerty K. M. 1992. Insider trading and the efficiency of stock prices. The RAND Journal of Economics, 106-122.

Fulghieri P, Lukin D. 2001. Information production, dilution costs, and optimal security design. Journal of Financial Economics, 61(1), 3-42.

Furfine, C. H. 2003. Decimalization and market liquidity. Economic Perspectives. 27(4), 2-12.

Gao P, Liang P. J. 2013. Informational feedback effect, adverse selection, and the optimal disclosure policy. Journal of Accounting Research, 51(5), 1133-1158.

Garvey, G. T. 1997. Marketable incentive contracts and capital structure relevance. The Journal of Finance, 52:35378.

Goldstein, I., Ozdenoren, E., and Yuan, K. 2011. Learning and complementarities in speculative attacks. The Review of Economic Studies, 78(1), 263-292.

Gorton G, Huang L. X., Kang Q. 2013. The limitations of stock market efficiency: price informativeness and CEO turnover. Working Paper.

Hadlock, C. J., Pierce, J. R. 2010. New evidence on measuring financial constraints: Moving beyond the KZ index. Review of Financial Studies, 23(5), 1909-1940.

Harris, M., and A. Raviv. 1990. Capital Structure and the Informational Role of Debt. The Journal of Finance, 45, 32149.

Hart, O., and J. Moore. 1995. Debt and Seniority: An Analysis of the Role of Hard Claims in Constraining Management. The American Economic Review, 85, 56785. 
Hicks, J. R. 1935. Annual survey of economic theory: the theory of monopoly. Econometrica 3, 120 .

Holmstrom, B., and Milgrom, P. 1987. Aggregation and linearity in the provision of intertemporal incentives. Econometrica: Journal of the Econometric Society, 303-328.

Holmstrm, B. and Tirole, J. 1993. Market liquidity and performance monitoring. Journal of Political Economy, 678-709.

Jayaraman, S., and Milbourn, T. T. 2012. The role of stock liquidity in executive compensation. The Accounting Review, 87(2), 537-563.

Jensen, M. C. 1986. Agency Costs of Free Cash Flow, Corporate Finance, and Takeovers. American Economic Review 76:323.

Jensen, M. C. 1993. The Modern Industrial Revolution, Exit, and the Failure of Internal Control Systems. The Journal of Finance 48:83180.

Kang, Q., Liu, Q. 2008. Stock trading, information production, and executive incentives. Journal of Corporate Finance, 14(4), 484-498.

Kang, Q., Liu, Q. 2010. Information-based stock trading, executive incentives, and the principal-agent problem. Management Science, 56(4), 682-698.

Kaplan, S. N., Zingales, L. 1997. Do investment-cash flow sensitivities provide useful measures of financing constraints? Quarterly Journal of Economics, 112(1), 169-215.

Khanna N, Slezak S. L., Bradley M. 1994. Insider trading, outside search, and resource allocation: why firms and society may disagree on insider trading restrictions. Review of Financial Studies, 22(2), 575-608.

Kyle, A. S. 1985. Continuous auctions and insider trading. Econometrica: Journal of the Econometric Society, 1315-1335.

Luo Y. 2005. Do insiders learn from outsiders? Evidence from mergers and acquisitions. Journal of Finance, 60(4), 1951-1982. 
Marris, R. 1964. The economic theory of managerial capitalism. Vol. 258 Macmillan London.

Masulis, R. W., C. Wang, and F. Xie. 2007. Corporate governance and acquirer teturns. The Journal of Finance, 62, 1851-1889.

Shleifer, A., and R. W. Vishny. 1997. A survey of corporate governance. The Journal of Finance, 52, 737-783.

Stulz, R. 1990. Managerial discretion and optimal financing policies. Journal of Financial Economics, 26:327.

Subrahmanyam A, Titman S. 1999. The going public decision and the development of financial markets. Journal of Finance 54(3), 1045-1082.

Titman, S., K. C. J. Wei, and F. Xie. 2004. Capital investments and stock returns. Journal of Financial and Quantitative Analysis, 39, 677-700.

Williamson, O. E. 1964. The economics of discretionary behavior: managerial objectives in a theory of the firm. Prentice-Hall.

Zwiebel, J. 1996. Dynamic capital structure under managerial entrenchment. The American Economic Review, 86, 1197-1215. 